\title{
Nocturnal low-level clouds in the atmospheric boundary layer over southern West Africa: an observation-based analysis of conditions and processes
}

\author{
Bianca Adler $^{1}$, Karmen Babić ${ }^{1}$, Norbert Kalthoff ${ }^{1}$, Fabienne Lohou ${ }^{2}$, Marie Lothon ${ }^{2}$, Cheikh Dione $^{2}$, \\ Xabier Pedruzo-Bagazgoitia ${ }^{3}$, and Hendrik Andersen ${ }^{1}$ \\ ${ }^{1}$ Institute of Meteorology and Climate Research, Karlsruhe Institute of Technology (KIT), Karlsruhe, Germany \\ ${ }^{2}$ Laboratoire d'Aérologie, Université de Toulouse, CNRS, UPS, Toulouse, France \\ ${ }^{3}$ Meteorology and Air Quality Group, Wageningen University and Research, Wageningen, the Netherlands
}

Correspondence: Bianca Adler (bianca.adler@kit.edu)

Received: 27 July 2018 - Discussion started: 5 September 2018

Revised: 3 January 2019 - Accepted: 4 January 2019 - Published: 17 January 2019

\begin{abstract}
During the West African summer monsoon season, extended nocturnal stratiform low-level clouds (LLCs) frequently form in the atmospheric boundary layer over southern West Africa and persist long into the following day affecting the regional climate. A unique data set was gathered within the framework of the Dynamics-AerosolChemistry-Cloud Interactions in West Africa (DACCIWA) project, which allows, for the first time, for an observational analysis of the processes and parameters crucial for LLC formation. In this study, in situ and remote sensing measurements from radiosondes, ceilometer, cloud radar and energy balance stations from a measurement site near Savè in Benin are analyzed amongst others for 11 nights. The aim is to study LLC characteristics, the intranight variability of boundary layer conditions and physical processes relevant for LLC formation, as well as to assess the importance of these processes. Based on the dynamic and thermodynamic conditions in the atmospheric boundary layer we distinguish typical nocturnal phases and calculate mean profiles for the individual phases. A stable surface inversion, which forms after sunset, is eroded by differential horizontal cold air advection with the Gulf of Guinea maritime inflow, a cool air mass propagating northwards from the coast in the late afternoon and the evening, and shear-generated turbulence related to a nocturnal low-level jet. The analysis of the contributions to the relative humidity changes before the LLC formation reveals that cooling in the atmospheric boundary layer is crucial to reach saturation, while specific humidity changes play a minor role. We quantify the heat budget terms and find that
\end{abstract}

about $50 \%$ of the cooling prior to LLC formation is caused by horizontal cold air advection, roughly $20 \%$ by radiative flux divergence and about $22 \%$ by sensible heat flux divergence in the presence of a low-level jet. The outcomes of this study contribute to the development of a conceptual model on LLC formation, maintenance and dissolution over southern West Africa.

\section{Introduction}

Nocturnal stratiform low-level clouds (LLCs) frequently form in the atmospheric boundary layer (ABL) over southern West Africa during the West African summer monsoon season. These LLCs have typical cloud-base heights (CBHs) of only a few hundred meters above ground (Schrage and Fink, 2012; Kalthoff et al., 2018) and cover an area of about $800000 \mathrm{~km}^{2}$ (van der Linden et al., 2015). The LLCs form during the night and persist long into the following day (Kalthoff et al., 2018). They thus affect the energy balance at the Earth's surface, the diurnal cycle of the ABL and the regional climate (Knippertz et al., 2011; Hannak et al., 2017). Numerical weather prediction and climate models still struggle to correctly represent the West African monsoon (Hannak et al., 2017), which may be related to the erroneous representation of the LLCs. A profound and accurate understanding of the processes relevant for the formation, maintenance and dissolution of the LLCs might help to identify flaws in these models. 
Most of our knowledge on the processes relevant for LLCs is based on numerical simulations, as high-quality observational data are scarce in this region. Studies by Schrage and Fink (2012), Schuster et al. (2013), Adler et al. (2017) and Deetz et al. (2018) suggest that processes spanning from the microscale to the synoptic scale are important such as horizontal cold air advection, orographic lifting, lifting related to gravity waves and shear-generated vertical mixing underneath the axis of a nocturnal low-level jet (LLJ). There is evidence that the horizontal cold air advection is related to the southwesterly monsoon flow, which transports maritime air from the Gulf of Guinea northwards over land. The daytime conditions at the coast are characterized by a superposition of the monsoon flow and a sea breeze. During the monsoon season, the strong southwesterly monsoon flow dominates and makes it difficult to distinguish between them (Bajamgnigni Gbambie and Steyn, 2013). During the day, the southwesterly flow is decelerated over land leading to convergence along a line parallel to the coast often associated with moist convection (Knippertz et al., 2017; Parker et al., 2017) and rainfall (Maranan et al., 2018). Model studies indicate that the convergence zone, which separates the cool maritime air in the south from the warmer air in the convective ABL over land, is rather stationary and located at several tens of kilometers distance from the coast until the late afternoon (Adler et al., 2017; Deetz et al., 2018). In the late afternoon and early evening, the cool maritime air starts to propagate inland and reaches distances of more than $100 \mathrm{~km}$. Grams et al. (2010) investigate a sea-breeze front that is stationary at the coast of Mauritania during daytime and propagates inland in the evening. These authors relate the stationarity to a balance between horizontal advection of cool maritime air and turbulence in the convective ABL over land, and link the inland propagation to the decay of turbulence in the late afternoon. As the maritime air, which propagates northwards in our investigation area in southern West Africa, has its origin over the Gulf of Guinea, we call this feature Gulf of Guinea maritime inflow and refer to it as maritime inflow hereafter for the sake of brevity.

To evaluate the hypotheses from previous studies and to enhance our understanding of the physical processes relevant for LLCs, high-quality comprehensive observations in the coastal region of southern West Africa were urgently needed. Therefore, a concerted measurement campaign was conducted during the summer monsoon season in June and July 2016 within the framework of the Dynamics-AerosolChemistry-Cloud Interactions in West Africa (DACCIWA) project (Knippertz et al., 2015). The meteorological measurements were airborne (Flamant et al., 2018) and ground-based at three supersites in Ghana, Benin and Nigeria (Kalthoff et al., 2018) and depict the most comprehensive data set for this region so far. With respect to climatological conditions, the period of the field campaign was characterized by Pacific La Niña and Atlantic El Niño and overall average rainfall across the whole of West Africa (Knippertz et al., 2017).

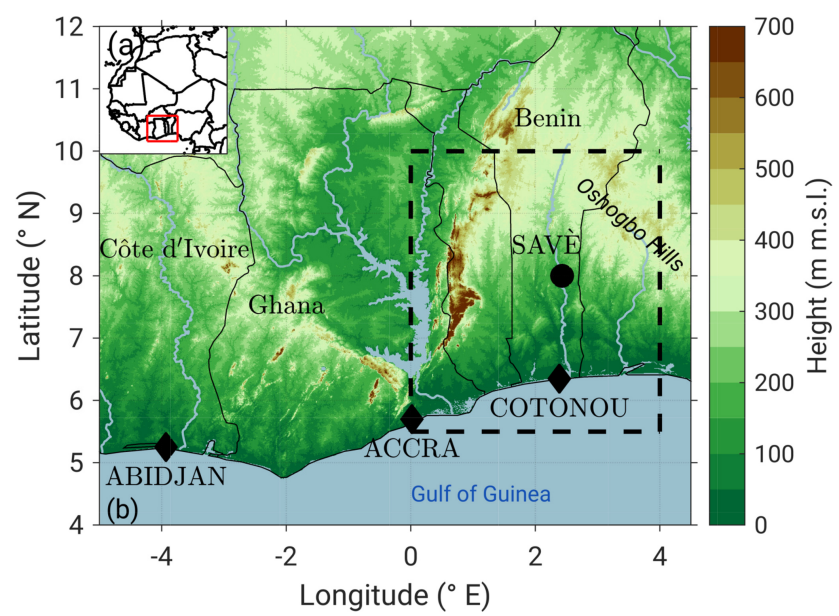

Figure 1. Location of the investigation area (red box) in southern West Africa (a) and topography in the investigation area with the location of the supersite Savè (Benin) and of the coastal radiosonde stations at Abidjan (Côte d'Ivoire), Accra (Ghana) and Cotonou (Benin) indicated (b). The hashed box indicates the area used for the analysis of the spatial distribution of LLC. Solid lines indicate country borders with country names given in (b).

Based on the observational data gathered at the groundbased supersite in Benin (Savè, location shown in Fig. 1), which is the supersite with the most comprehensive instrumentation, a series of analyses have been conducted on the LLCs: Babić et al. (2018) present, for the first time, a detailed analysis of the diurnal cycle of LLCs for a case study of a typical night (7-8 July, intensive observation period - IOP -8 ) and identify physical processes and factors that control the formation, maintenance and dissolution of LLCs at Savè. Based on the dynamic and thermodynamic conditions in the ABL during IOP 8, these authors identify different phases, which are outlined in Fig. 2. The stable phase describes a period after sunset when the horizontal wind is weak and a surface inversion forms. With the arrival of the maritime inflow a few hours after sunset, dynamic and thermodynamic conditions in the ABL change and are then characterized by a LLJ wind profile (jet phase). Eventually, LLCs form (stratus phase). About $1 \mathrm{~h}$ after sunrise, the cloud base starts rising due to the evolution of the convective ABL (convective phase). Babić et al. (2018) determine the contributions of temperature and specific humidity changes to the relative humidity changes and quantify the heat budget terms for the different phases during IOP 8 using radiosoundings. Dione et al. (2018) perform a detailed statistical analysis on the characteristics of the LLCs and the low-level atmospheric dynamics using mainly data from continuously running remote sensing instruments for a 41-day period. While the studies of Babić et al. (2018) and Dione et al. (2018) either look at the diurnal cycle during one case study or at mean quantities during a longer measurement period, the present analysis focuses on 11 IOP nights. As radiosoundings were per- 


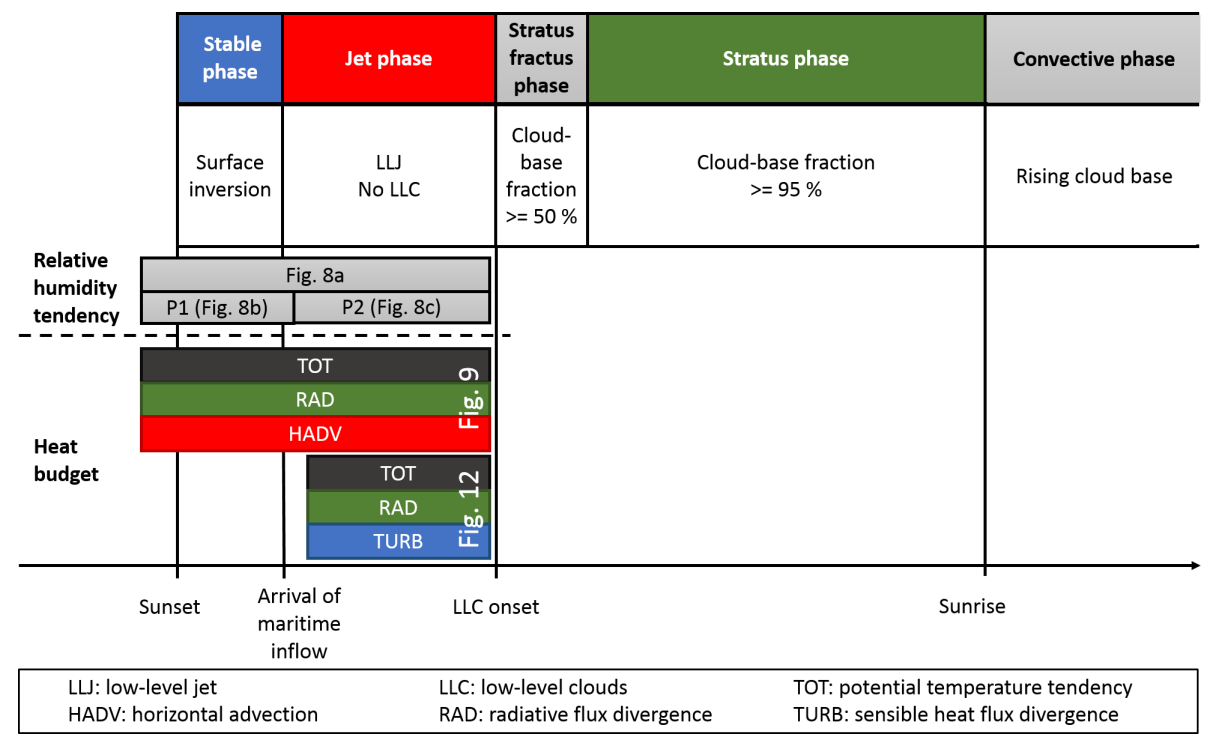

Figure 2. Schematic overview of the different phases including their main characteristics. The width of the boxes is a rough estimate of the mean duration of the individual phases. Note that the stratus fractus phase does not occur during all nights. The different time periods considered for the estimation of the relative humidity changes and the heat budget terms are indicated.

formed in short temporal intervals of 1 to $1.5 \mathrm{~h}$ throughout the IOP nights, high-quality profile information on temperature, specific humidity and horizontal wind are available, which allows us to perform an analysis for these nights in a manner consistent with the methods used by Babić et al. (2018). By analyzing several nights, instead of one, we are able to address the representativeness of the results obtained from the single case study and to generalize some of the findings. Besides the generalization of process relevance for the formation of LLCs, we aim to characterize the LLCs and to investigate the intranight variability of ABL conditions. The research questions to be answered are the following: (i) What are the temporal and spatial characteristics of LLCs? (ii) How do ABL conditions change during the different nocturnal phases? (iii) What dominates the relative humidity changes and heat budget? (iv) How do the processes involved in question (iii) vary with height and from night to night?

In Sect. 2, the observational data used and the methods applied to derive different LLC characteristics and to estimate the heat budget terms are described. Section 3 includes LLC characteristics and Sect. 4 the conditions in the nocturnal ABL for the different phases. In Sect. 5, relative humidity changes and heat budget terms are investigated and processes resulting in LLC formation are assessed. In Sect. 6, the observed processes are discussed in comparison to recent studies, followed by a summary and conclusions in Sect. 7 .

\section{Data used and methods}

\subsection{Measurement site and instrumentation}

The supersite at Savè ( $166 \mathrm{~m}$ a.m.s.l. - meters above mean sea level) was located in Benin about $185 \mathrm{~km}$ inland from the coast (Fig. 1b). The terrain in the immediate surrounding of the site is rather flat, while higher terrain up to $500 \mathrm{~m}$ a.m.s.l. is found to the north and east of it. During the 7 weeks of the ground-based measurement campaign, comprehensive in situ and remote sensing measurements were conducted. A detailed overview of the atmospheric conditions during the whole campaign period is given by Kalthoff et al. (2018) and the complete instrumentation including information on the manufacturers is described by Bessardon et al. (2018). In this study, we use data from the continuously running ceilometer (measuring backscatter profiles from which information on $\mathrm{CBH}$ is derived) and cloud radar (measuring radar reflectivity profiles from which information on cloud-top heights - CTHs - is derived) to obtain information on the LLC characteristics at Savè. Spatiotemporal information on LLCs in a larger area around Savè $\left(0-4^{\circ} \mathrm{E}\right.$ and $5.5-10^{\circ} \mathrm{N}$, hashed box in Fig. 1b) is obtained from the Spinning Enhanced Visible and Infrared Imager (SEVIRI) sensor (Schmetz et al., 2002). Two energy balance stations provide the near-surface radiation and energy balances and meteorological parameters over two types of land use (fallow and corn) and an ultra-high frequency (UHF) wind profiler and a Doppler lidar are used to obtain information on the horizontal and vertical wind. Ceilometer, cloud radar, one of the energy balance stations and the Doppler lidar are part of the mobile integrated atmospheric observation system "KITcube" 
Table 1. IOP numbers; corresponding dates; and mean potential temperature, specific humidity, horizontal wind speed and wind direction in the lower $1000 \mathrm{~m}$ at the coast and Savè during the DACCIWA ground-based field campaign. Values are obtained from the radiosoundings in the late afternoon and averaged for all three coastal stations if available. IOPs not used in this study are written in italic font.

\begin{tabular}{llrrrr}
\hline IOP & Dates & $\begin{array}{r}\text { Potential } \\
\text { temperature (K) } \\
\text { Coast/Savè }\end{array}$ & $\begin{array}{r}\text { Specific } \\
\text { humidity } \\
\left(\mathrm{g} \mathrm{kg}^{-1}\right) \\
\text { Coast/Savè }\end{array}$ & $\begin{array}{r}\text { Wind speed } \\
\left(\mathrm{m} \mathrm{s}^{-1}\right) \\
\text { Coast/Savè }\end{array}$ & $\begin{array}{r}\text { Wind } \\
\text { direction } \\
\text { (degree) } \\
\text { Coast/Savè }\end{array}$ \\
\hline 1 & 17-18 June & $-/ 302.2$ & $-/ 15.0$ & $-/ 3.3$ & $-/ 219$ \\
2 & 20-21 June & $300.0 / 300.4$ & $15.9 / 15.9$ & $10.9 / 14.4$ & $214 / 193$ \\
3 & 25-26 June & $299.7 / 302.7$ & $16.1 / 17.2$ & $7.8 / 2.8$ & $228 / 176$ \\
4 & 28-29 June & $299.9 / 302.2$ & $15.8 / 16.8$ & $7.3 / 3.2$ & $224 / 177$ \\
5 & 30 June-1 July & $300.4 / 302.5$ & $15.5 / 16.1$ & $6.8 / 3.4$ & $233 / 210$ \\
6 & 2-3 July & $300.0 / 303.5$ & $16.0 / 17.1$ & $3.9 / 2.1$ & $183 / 116$ \\
7 & 4-5 July & $299.9 / 303.5$ & $16.8 / 16.6$ & $7.4 / 5.4$ & $218 / 186$ \\
8 & 7-8 July & $300.4 / 303.4$ & $16.8 / 16.8$ & $7.2 / 0.9$ & $235 / 259$ \\
9 & 10-11 July & $299.8 / 303.0$ & $16.5 / 16.8$ & $10.8 / 9.6$ & $228 / 201$ \\
10 & 13-14 July & $299.9 / 301.4$ & $14.9 / 13.6$ & $5.5 / 3.7$ & $250 / 301$ \\
11 & 17-18 July & $299.0 / 302.4$ & $16.0 / 15.7$ & $7.4 / 5.0$ & $206 / 207$ \\
12 & 20-21 July & $299.7 / 301.0$ & $14.8 / 16.8$ & $7.8 / 5.6$ & $248 / 246$ \\
13 & 23-24 July & $299.4 / 301.4$ & $13.3 / 16.8$ & $9.0 / 2.3$ & $250 / 247$ \\
14 & 26-27 July & $298.4 / 301.7$ & $14.8 / 15.6$ & $4.9 / 2.9$ & $232 / 172$ \\
15 & 29-30 July & $299.0 / 302.6$ & $15.0 / 15.0$ & $4.0 / 2.2$ & $200 / 215$ \\
\hline
\end{tabular}

deployed by the Karlsruhe Institute of Technology (Kalthoff et al., 2013).

During the 7 weeks of the campaign, 15 IOPs in total were conducted (Table 1). Every IOP lasted from the late afternoon throughout the night until the afternoon of the following day to capture the whole diurnal cycle of the LLCs. Although we aimed to perform IOPs during synoptically undisturbed nights without any mesoscale convective systems, the conditions during 3 of the 15 IOPs (IOPs 2, 12 and 13) were disturbed by rain at or near the supersite, preventing the evolution of "typical" LLCs. This is why we exclude these IOPs from this analysis. No LLCs existed at Savè during IOP 10. This IOP was within the vortex period during which a drier air mass was present in the investigation area (Kalthoff et al., 2018). A detailed analysis of the differences between nights with and without LLCs is the topic of another upcoming publication. This leaves 11 IOPs for the analysis of the relationship between ABL conditions and LLCs (the used IOPs are indicated in Table 1). IOP 1 falls into the preonset phase of the monsoon and the other 10 IOPs into phases during which the monsoon conditions are relatively undisturbed and the strength and position of the Saharan heat low and African easterly jet are close to the climatological average (Knippertz et al., 2017). During IOPs, radiosondes were released at Savè $1 \mathrm{~h}$ before the nominal times at 00:00, 06:00, 12:00 and 18:00 UTC. The first radiosounding was released at 17:00 UTC (the local standard time in Benin is UTC+1), in order to be synchronous with the soundings at operational radiosonde stations. In between, so-called frequent radiosondes were launched reaching max- imum heights of around $1500 \mathrm{~m}$ a.g.l. (meters above ground level) to get a higher temporal resolution of the ABL conditions. These sondes are attached to two balloons of different volumes, whereas the line to the larger balloon is cut after a preset time of ascent (corresponding to around $1500 \mathrm{~m}$ a.g.1.) initiating a controlled descent of the sonde (Legain et al., 2013). This method allows for a reuse of the sonde and short sounding intervals. During IOPs 1-6, frequent radiosondes were launched at hourly intervals starting at 21:00 UTC. After IOP 7, the sounding schedule was changed to $1.5 \mathrm{~h}$ intervals starting at 18:30 UTC to better resolve the early evolution of the nocturnal ABL. An impression of the radiosonde schedule during individual IOPs can be obtained from Fig. 3 with each colored column indicating one sounding centered on the launch time.

In addition and as part of the DACCIWA radiosonde campaign (Flamant et al., 2018) radiosoundings at up to $6 \mathrm{~h}$ intervals were launched at three stations along the coast: Abidjan (Côte d'Ivoire), Accra (Ghana) and Cotonou (Benin) (locations are given in Fig. 1b).

\subsection{LLC characteristics}

\subsubsection{Cloud-base and cloud-top height detection}

From the ceilometer backscatter profiles with $1 \mathrm{~min}$ resolution, up to three CBHs are obtained using the manufacturer algorithm, which is based on a threshold method (we only use the lowest $\mathrm{CBH}$ in this study). The cloud radar deployed at Savè is dual-polarized, i.e., it is possible to distinguish between hydrometeors and other targets. The classification 

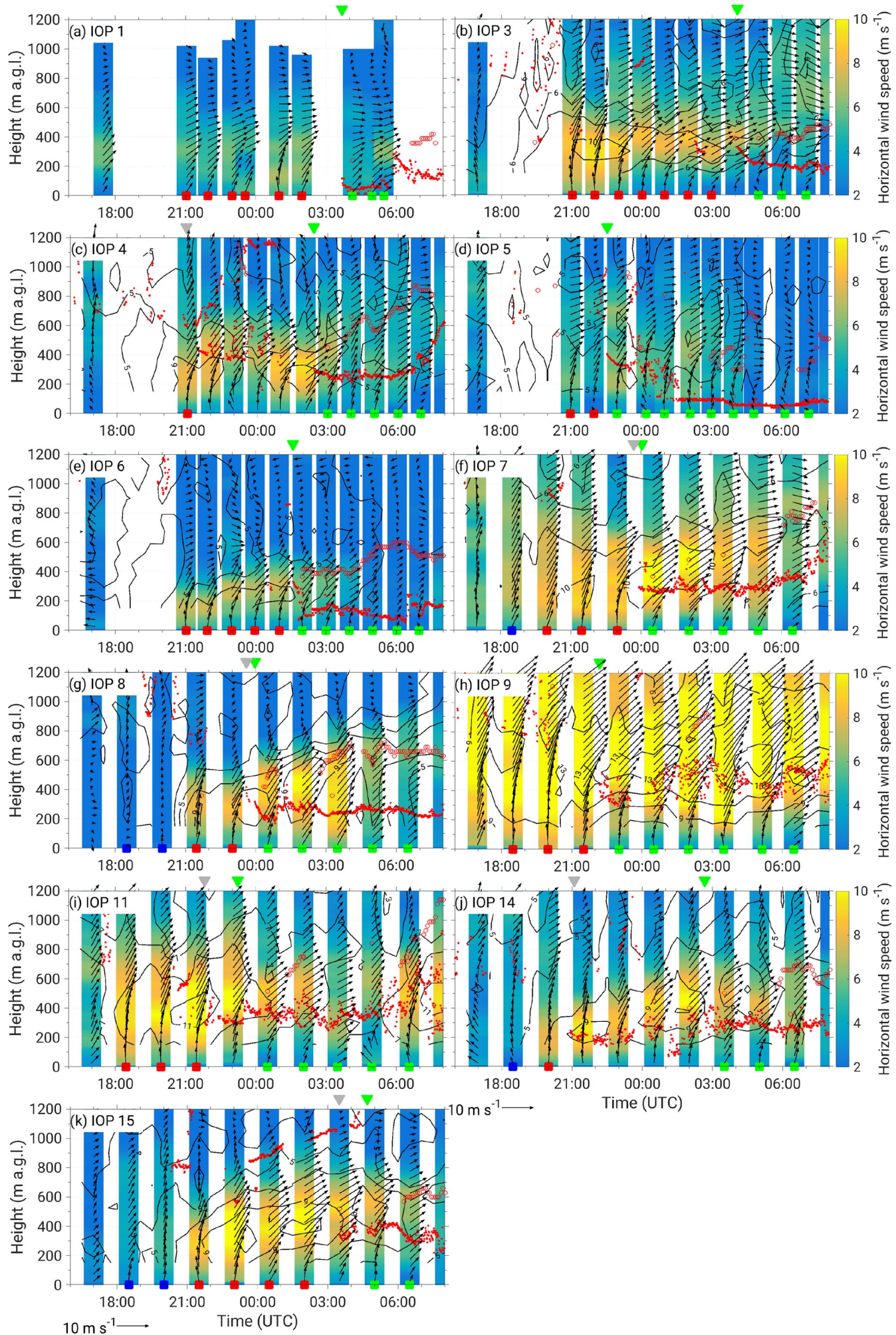

Figure 3. Horizontal wind speed from radiosondes (color coded) and from the UHF profiler (contour, $2 \mathrm{~m} \mathrm{~s}^{-1}$ increments) and horizontal wind vector from radiosondes (arrows) for IOPs analyzed in this study. The vertical bars are centered on the launch times of the radiosondes. Red dots indicate cloud base from ceilometer measurements and red circles cloud top from cloud-radar measurements. At the top of each plot the onset time of stratus is indicated by the green triangle. The gray triangle marks the onset time of stratus fractus if it occurred during the respective night. Blue, red and green squares at the bottom of each plot indicate radiosoundings considered in the averaged profiles for the stable, jet and stratus phases. 
uses the linear depolarization ratio and multipeak moments and is described in detail in Bauer-Pfundstein and Görsdorf (2007). From the radar reflectivity of hydrometeors we estimate the CTH for $5 \mathrm{~min}$ averaged reflectivity profiles applying a threshold of $-35 \mathrm{dBz}$, i.e., reflectivities larger than $-35 \mathrm{dBz}$ are considered clouds. As the reflectivity changes abruptly near $\mathrm{CTH}$, the determined CTHs are not sensitive to the applied threshold value. Examples of ceilometer backscatter profiles and cloud radar reflectivity profiles with estimated CBHs and CTHs are shown in Fig. 3 of Babić et al. (2018). Besides information on dynamic and thermodynamic conditions, estimates of the vertical extent of clouds can be obtained from relative humidity profiles measured with radiosondes. The algorithm uses a threshold of $99 \%$ and is described in Kalthoff et al. (2018). The CTHs used in this study are a combination of estimates from cloud radar and radiosonde measurements. During some soundings, discrepancies occur between CTHs estimated from cloud radar and radiosonde measurements, which are likely related to condensation of water vapor on the sensors when the radiosonde flies through a cloud (more details on this are given in Babić et al., 2018).

\subsubsection{Estimation of LLC onset time}

Before estimating onset times of LLCs from ceilometer data a clear definition of LLCs must be stated. Do we require a constant CBHs and a complete coverage of the sky or do we allow some variability in CBHs and coverage? From the overview of CBH in Kalthoff et al. (2018), we expect LLC bases to mainly occur in the lower $600 \mathrm{~m}$ and consequently choose this layer to estimate cloud-base fraction from ceilometer data. As CBHs are available every minute from the ceilometer we calculate the cloud-base fraction every minute for the subsequent $60 \mathrm{~min}$. The onset time is then defined as the first point in time when a cloud base is detected in the lower $600 \mathrm{~m}$ and the subsequent cloudbase fraction is higher than a respective threshold. During all IOP nights, cloud-base fractions reach $100 \%$. During some nights, cloud-base fractions shift almost instantly from $0 \%$ to $100 \%$, while during other nights, lower cloud-base fractions precede the complete coverage by several hours. To take this into account, we introduce the stratus fractus phase before the stratus phase, in addition to the phases identified by Babić et al. (2018) for IOP 8 (Fig. 2). We choose two thresholds, $50 \%$ and $95 \%$, to detect the onset of stratus fractus and stratus, respectively. For the estimation of tendencies and contributions we look at the period before the onset of stratus fractus, to avoid the impact of phase changes, while we investigate the modification of the ABL conditions by the LLCs for the stratus phase only, as we expect a clearer signal from this phase.

\subsubsection{Detection of the horizontal distribution of LLCs}

Detecting LLCs during the night from the geostationary SEVIRI sensor is challenging, as the temperature at the cloud top is very close to the surface temperature in cloud-free regions, making them nearly indistinguishable from the surface in the infrared channels. In the absence of high or mid-level clouds, which are obscuring the LLCs from the view of the satellite-borne sensor, the brightness temperature difference of the thermal infrared channel at $10.8 \mu \mathrm{m}$ and the middleinfrared channel at $3.9 \mu \mathrm{m}$ are used to visualize the LLCs during the night. Higher-level clouds are masked out by applying a brightness temperature threshold of $283 \mathrm{~K}$ to the $10.8 \mu \mathrm{m}$ channel, i.e., cloud tops above around $2500 \mathrm{~m}$ a.m.s.l. are masked. More details on the method are given in Babić et al. (2018).

\subsection{Estimation of heat budget terms}

The tendency of the mean potential temperature (TOT) is generally influenced by various processes such as horizontal (HADV) and vertical (VADV) advection, radiative flux divergence (RAD), sensible heat flux divergence (TURB) and phase changes (SQ) (e.g., Stull, 1988):

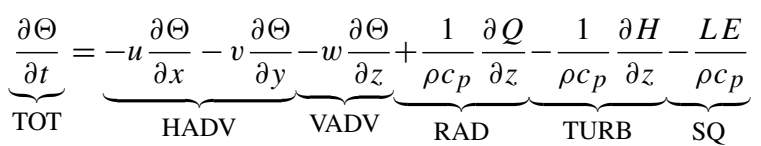

with the mean potential temperature, $\Theta$; the mean wind components, $u, v$ and $w$; the mean air density, $\rho$; the specific heat capacity at constant pressure, $c_{p}$; the sensible heat flux, $H$; the latent heat of vaporization of water, $L$; and the evaporation rate, $E$. The estimation of the different heat budget terms from observations is challenging and requires some assumptions. The easiest term to derive is TOT, which we calculate directly from radiosonde profiles. As we only consider periods without LLCs, we can neglect SQ in the budget. Sun et al. (2003) calculate radiative and sensible heat flux divergence from tower measurements for the nocturnal $\mathrm{ABL}$ and find that even small vertical or horizontal temperature differences can contribute significantly to TOT. The measurement accuracy of mean vertical velocity required to estimate VADV is hardly achieved by in situ wind measurements and even less by remote sensing instruments. This is why we cannot estimate VADV in this study. This leaves us with HADV, RAD and TURB for which we now describe the methods we used for their estimations. The estimations are done for different periods (Fig. 2). The period for HADV comprises the stable and jet phases, while TURB is calculated during the jet phase only, and RAD and TOT are estimated for both time periods.

\subsubsection{Horizontal temperature advection}

The large-scale dynamic and thermodynamic conditions in the investigation area in southern West Africa are characterized by the southwesterly monsoon flow and a meridional 
temperature gradient with lower temperatures over the Gulf of Guinea. As outlined in the introduction, there is evidence that cool maritime air is transported further inland with the monsoon flow during the late afternoon and evening - a feature that we call maritime inflow. During the IOP nights studied here, we detect a concurrent increase in wind speed with the profile showing a LLJ structure and a decrease in temperature in a layer of several hundred meters depth during the first half of the night, which we interpret as the arrival of the maritime inflow at Savè. The changes in atmospheric conditions during this arrival are nicely illustrated for IOP 8 in Babić et al. (2018). In the present study, we use radiosoundings to detect the changes in temperature and wind profiles. We manually distinguish between the different phases and allocate the radiosonde profiles to the phases. Note that Dione et al. (2018) find some differences in the onset times of the LLJ and the maritime inflow when analyzing the whole campaign period. These differences may depend on the higher temporal resolution of the data from continuous remote sensing instruments and on the criteria applied by these authors to detect the onset times.

In order to estimate horizontal cold air advection related to the maritime inflow from the available observations, several assumptions are necessary, which are illustrated in the schematic drawing in Fig. 4. To estimate the meridional temperature difference, we use radiosoundings performed at the three coastal stations and at Savè in the late afternoon (station locations in Fig. 1b). We assume that the temperature distribution is homogeneous along the coast and that the zonal temperature gradient and wind component are small and make the following estimates for a meridional cross section through Savè. The difference of the mean temperature in the late afternoon between the coast and Savè is more than $3 \mathrm{~K}$ on the average (Table 1 ). Information on the daytime meridional temperature distribution between Savè and the coast are obtained from aircraft flights, when horizontal legs were flown in the ABL at some angle to the coast line in the afternoon (not shown). These measurements indicate that the aircraft passes through the maritime inflow and through the convective ABL over the land during these flights. In the convective ABL, the temperature is rather horizontally homogeneous, while it decreases gradually towards the coast within a certain distance from the coast. We interpret this distance as the maximum inland propagation of the maritime inflow in the late afternoon, i.e., as the location of the convergence zone that separates the cool maritime air in the south from the warmer air in the convective ABL (right edge of yellow box in Fig. 4). This means that the temperature decreases gradually within the maritime inflow and we assume a linear increase in temperature in the south-north direction in the maritime inflow and a constant temperature in the convective ABL (red curve in Fig. 4). Motivated by model studies by Adler et al. (2017) and Deetz et al. (2018), we expect the maximum inland propagation to be somewhere between 50 and $125 \mathrm{~km}$ inland from the coast in the late afternoon.

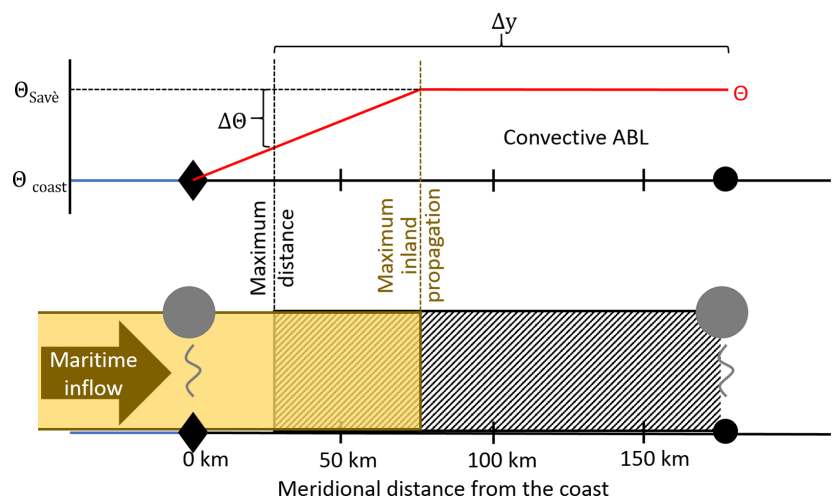

Figure 4. Schematic drawing illustrating the assumptions made for the estimation of horizontal advection using the example of a maximum inland propagation of the marine inflow of $75 \mathrm{~km}$ in the afternoon. In the bottom half, the different air masses are indicated: the cool maritime inflow (yellow area) is propagating inland from the south. The vertical dashed yellow line indicates the maximum inland propagation in the late afternoon. The propagation speed and the onset time of LLCs determine the maximum distance from which the air mass reaching Savè before the LLC onset may originate (hashed area). Radiosoundings are performed at the coast (diamond) and at Savè (circle). In the upper half of the figure, the meridional potential temperature distribution, $\Theta$, is displayed. In the maritime inflow, the temperature increases linearly northwards from the coast, while it is constant in the continental ABL. For the estimation of horizontal advection, $\Delta \Theta$ and $\Delta y$ are used.

For the cooler air of the maritime inflow to be able to produce a cooling at Savè, the maritime inflow has to propagate far enough inland to reach the site. To estimate the maximum distance from which the air mass measured at Savè before the LLC onset may originate (left edge of the hashed area in Fig. 4), we estimate the propagation speed from radiosoundings. Therefore, we average the meridional component of the coastal wind profile in the afternoon and of the wind profile at Savè after the maritime inflow arrives, $v$, and assume that the maritime inflow propagates with the maximum southerly wind component of the averaged vertical profile. If the propagation speed is high enough and the LLC onset late enough, the air in the maritime inflow is able to reach Savè and to contribute to the cooling before the LLC onset. For example, assuming a propagation speed of $5 \mathrm{~m} \mathrm{~s}^{-1}$, a LLC onset at Savè at midnight and a start time of the further inland propagation of the maritime inflow at 16:00 UTC, the air mass passing Savè originates at a maximum distance of $41 \mathrm{~km}$ inland from the coast. With an assumed maximum inland propagation of the maritime inflow of $75 \mathrm{~km}$ during the day, parts of the air mass passing Savè before the LLC onset are of maritime origin and have a $\Delta \Theta$ lower temperature than the air in the convective ABL. Based on the assumptions for the maximum distance and the linear temperature change in the maritime inflow (Fig. 4), HADV is calculated as $-v \Delta \Theta \Delta y^{-1}$ using data from all three coastal stations (Abidjan, Accra and 


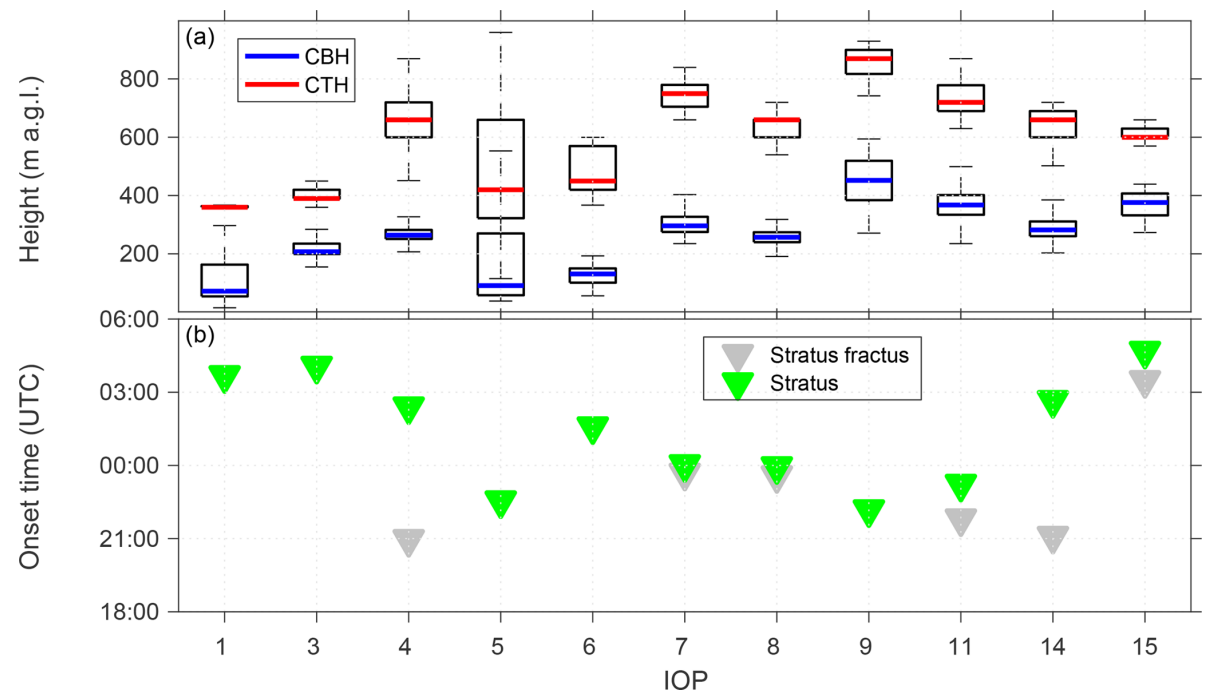

Figure 5. Cloud-base height $(\mathrm{CBH})$ and cloud-top height $(\mathrm{CTH})$ during the stratus phase (a). The blue and red bars indicate median $\mathrm{CBH}$ and $\mathrm{CTH}$, respectively, the top and bottom edges of the boxes represent the 75 th and 25 th percentiles and the whiskers extreme values. Onset time of stratus and stratus fractus (if it occurred) estimated from ceilometer measurements derived with the methods described in Sect. 2.2.2 (b).

Cotonou), if available, and four different maximum inland propagation distances $(50,75,100$ and $125 \mathrm{~km})$.

\subsubsection{Radiative flux divergence}

To estimate the contribution of RAD to the temperature tendency at Savè, we apply the Santa Barbara DISORT Atmospheric Radiative Transfer (SBDART) model (Ricchiazzi et al., 1998) to the mean profile averaged for the time period between 17:00 UTC and the formation of clouds and for the jet phase (Fig. 2) using a mean aerosol optical depth measured with the sun photometer at Savè and averaged for the months June and July 2016. More details on the radiative transfer model and on the input parameters used can be found in Babić et al. (2018).

\subsubsection{Sensible heat flux divergence}

During the night, the absolute value of the sensible heat flux is usually at its maximum at the surface and decreases with height (e.g., Sun et al., 2003). To estimate TURB from the existing measurements we need to make an assumption for the height where the sensible heat flux vanishes. In the presence of a surface inversion, this height is usually assumed to be the top of the surface inversion. If a LLJ is present, we assume that the sensible heat flux vanishes at the height of the LLJ axis (as vertical wind shear vanishes). Both cases are present at Savè during the stable phase and jet phase, respectively. Due to the insufficient number of radiosonde profiles during the stable phase (in particular during the IOPs 1-6), we estimate TURB for the jet phase only (Fig. 2). For this estimation we use measurements of the surface sensible heat flux at both energy balance stations and vertical profiles of horizontal wind to detect the height of the LLJ axis. The surface sensible heat flux is averaged over the considered time period and the bulk cooling by TURB is then estimated for the layer below the LLJ axis.

\section{LLC characteristics}

This section overviews the vertical distribution and temporal evolution of LLCs at Savè using ground-based remote sensing instruments and the horizontal distribution of LLCs using satellite images.

The combination of ceilometer and cloud-radar measurements allows us to obtain information on the vertical extent of the LLCs. In Fig. 3, the cloud base from ceilometer and cloud top from cloud-radar measurements are shown as red dots and circles, respectively, and Fig. 5a contains statistical information on CBHs and CTHs during the stratus phase for the individual IOPs. The median CBHs range from $70 \mathrm{~m}$ to $450 \mathrm{~m}$ a.g.l. and the median CTHs from 370 to $870 \mathrm{~m}$ a.g.l. When averaging the median heights and the vertical extents for all IOPs, $\mathrm{CBH}=250 \pm 120 \mathrm{~m}$ a.g.l., $\mathrm{CTH}=590 \pm$ $170 \mathrm{~m}$ a.g.l. and a vertical extent of $340 \pm 80 \mathrm{~m}$ result. This confirms the vertical extent of simulated LLCs (Schuster et al., 2013; Adler et al., 2017) and agrees with the median CBH and CTH pointed out by Dione et al. (2018) using all days of the DACCIWA campaign. During IOPs 1, 5 and 6, the median $\mathrm{CBH}$ is below $130 \mathrm{~m}$ a.g.l., while it is above $200 \mathrm{~m}$ a.g.l. for the other IOPs. This is in agreement with the two layers found favorable for $\mathrm{CBH}$ occurrence at Savè by Kalthoff et al. (2018) (see their Fig. 5) and will be taken up again in Sect. 5.3. 
From the $\mathrm{CBH}$ measured by the ceilometer the onset time of LLCs is derived by applying two thresholds for the cloudbase fraction (Sect. 2.2.2). The onset of stratus fractus and stratus is indicated by the gray and green markers, respectively, in Figs. 3 and 5b. In Fig. 3, these markers are placed at the top of each plot. Onset times and durations of both phases vary considerably for the individual IOPs. During some nights, long periods with stratus fractus precede stratus (e.g., $5.5 \mathrm{~h}$ during IOPs 4 and 14), while no stratus fractus at all is detected during other nights (IOPs 1, 3, 5, 6 and 9). The duration of the stratus phase varies between $2.3 \mathrm{~h}$ (IOP 15) and $8.8 \mathrm{~h}$ (IOP 9), assuming that the transition of the stratus to the convective phase starts at 07:00 UTC. On the average, the stratus fractus phase lasts for $1.3 \pm 2.1 \mathrm{~h}$ and the stratus phase for $5.6 \pm 2.3 \mathrm{~h}$. Stratus fractus occurs as early as 21:00 UTC (IOPs 4 and 14) and stratus onset times range from 22:00 UTC during IOP 9 to as late as 04:45 UTC during IOP 15. In the following we define the LLC onset time as the onset time of stratus fractus or of stratus if no stratus fractus is present. Note that Dione et al. (2018) detect the onset time of LLCs from an infrared camera, which took an image of some fraction of the sky every $2 \mathrm{~min}$. As this method strongly depends on the homogeneity of $\mathrm{CBH}$, cloud-base cover and cloud density, derived times sometimes differ from the stratus onset detected by ceilometer. The root-mean-square error between both methods is approximately $80 \mathrm{~min}$ for IOPs.

The horizontal distribution and evolution of LLCs is investigated using satellite images (Fig. 6) created with the method described in Sect. 2.2.3. Unfortunately, only during four IOPs are the LLCs in the surroundings of Savè not masked by high- or mid-level clouds, i.e., IOPs 3, 4, 7 and 8 . Despite the small sample size, the spatial LLC characteristics show a large variability with respect to the location of first LLC formation and to the directions of the subsequent growth:

1. During IOP 3, LLCs form already at 22:00 UTC over the higher terrain north and northeast of Savè (Fig. 1b) and remain more or less stationary until around 03:30 UTC expanding only a little (Fig. 6a). After that, the LLCs suddenly start to expand to the southwest until they cover most of the domain including Savè. This is in agreement with the onset of LLCs at around 04:00 UTC at Savè (Figs. 3b and 5b).

2. In the evening of IOP 4, some mid- and high-level clouds obscure the lower levels in many parts of the domain, but it is nevertheless evident that LLCs exists already at 21:00 UTC east of Savè over the higher terrain (Fig. 6b). In the following hours, the mid- and high-level clouds move westwards allowing for the detection of the growth of the LLCs towards the west affecting Savè. These LLCs have quite scattered cloud bases (Fig. 3c). Between around 00:30 and 02:30 UTC, a spatial gap occurs in the LLC deck right above Savè (Figs. 3c and 6b). After that, the LLCs cover most of the domain for the rest of the night (Fig. 6b). During this period, the CBHs are rather homogeneous, which is visible in the ceilometer measurements at Savè (Fig. 3c).

3. During IOP 7, the domain is mostly cloud free until 23:00 UTC (Fig. 6c). Then, LLCs start forming at several locations in the domain and grow during subsequent hours, also occurring at Savè after 00:00 UTC (Fig. 3f). After around 01:00 UTC, high-level clouds in a layer between around 11 and $13 \mathrm{~km}$ a.g.l. (as visible in cloudradar measurements at Savè) gradually move in from the east and cover the domain preventing the analysis of the further evolution of the LLCs.

4. During IOP 8, LLCs first form southwest and east of Savè after around 22:00 UTC (Fig. 6d). In the following hours both patches of LLCs expand, the one in the southwest reaching Savè at midnight (Fig. 3g). After 00:30 UTC both patches grow together. Subsequently, the LLCs expand in all directions and they cover most of the domain at sunrise.

Overall, we can identify two types of horizontal LLCs expansion. During IOPs 3, 4 and 8, the LLCs grow to the upstream side, i.e., towards the direction of the mean southwesterly flow, and to the downstream side, i.e., away from the direction of the mean flow. During IOP 7, LLCs form and grow at many locations at the same time with no clear direction being distinguishable. This suggests that different mechanisms are involved, and some of these are assessed in Sect. 5.3.

\section{Intranight variability of ABL conditions}

This section characterizes the mean nocturnal ABL conditions during different phases of the night - these are the LLCfree, stable and jet phases and the stratus phase (Fig. 2). The profiles that we use for the averaging during the individual phases are indicated at the bottom of each plot in Fig. 3 by the squares. To take into account the large variability in CBHs during the individual IOPs (Fig. 5a), we normalize the profiles with the median $\mathrm{CBH}$ of each IOP $(z / \mathrm{CBH})$. Despite the large day-to-day variability in the wind speed profiles (Fig. 3), there is a clear signal in the mean normalized profiles (Fig. 7a): during the stable phase, the mean wind speed is lowest with around $3 \mathrm{~m} \mathrm{~s}^{-1}$ and little variation with height, while the LLJ shape is clearly visible during the jet and stratus phases. During the jet phase, the LLJ axis with a maximum value of more than $7 \mathrm{~m} \mathrm{~s}^{-1}$ is near the height where cloud bases exist later on. In the presence of LLCs, the LLJ axis shifts upwards to around $z / \mathrm{CBH}=1.6$ and the maximum decreases by about $1 \mathrm{~m} \mathrm{~s}^{-1}$. The mean potential temperature decreases in the course of the night leading to an up to $4 \mathrm{~K}$ cooler atmosphere during the jet phase than during the stable phase and a decrease of about $1 \mathrm{~K}$ from the jet to the stratus phase (Fig. 7b). The strongest changes occur up to around 
(a) IOP 3
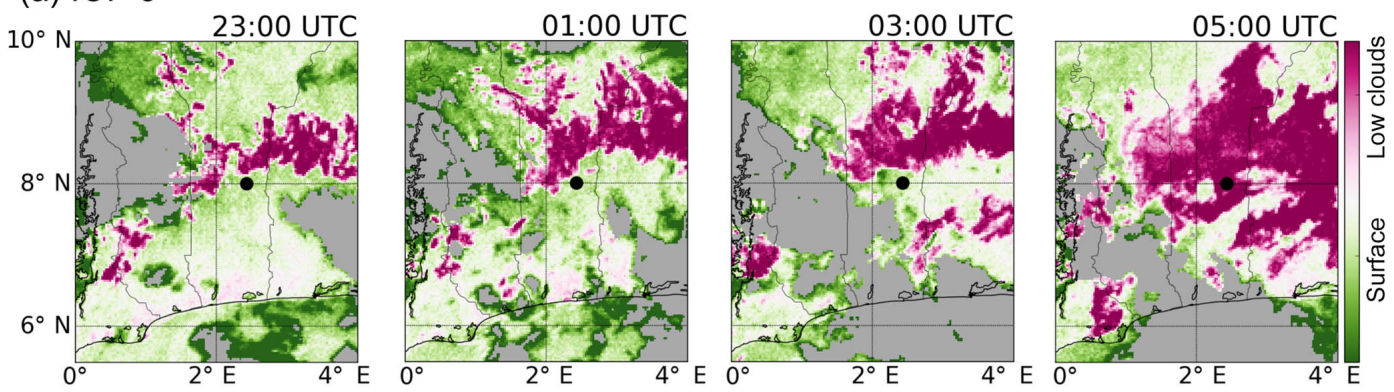

(b) IOP 4
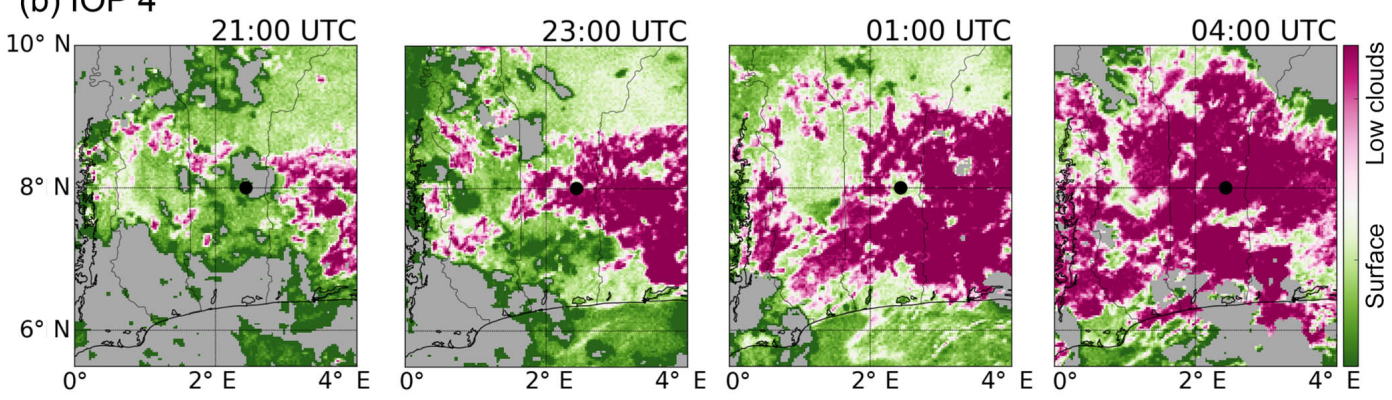

(c) IOP 7
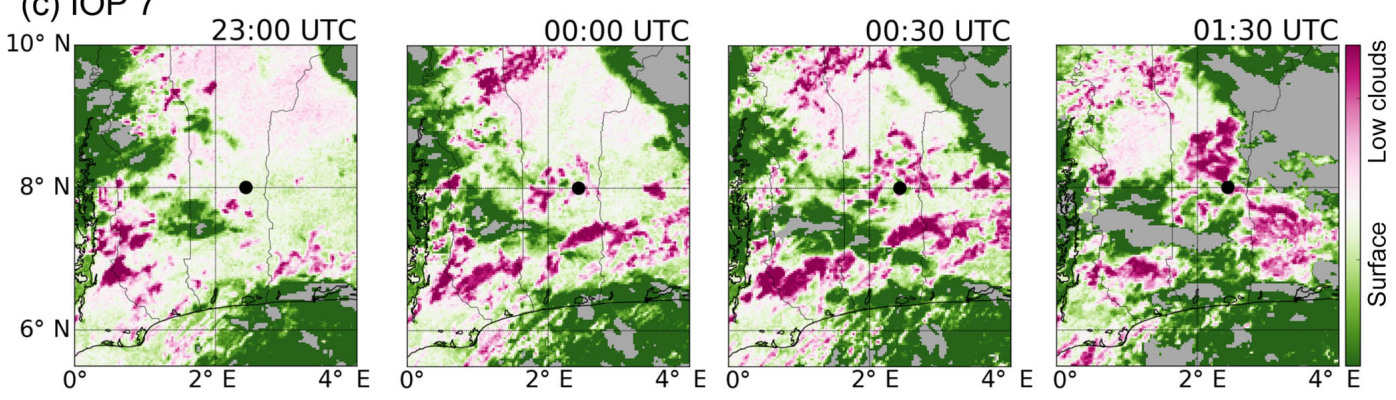

(d) IOP 8
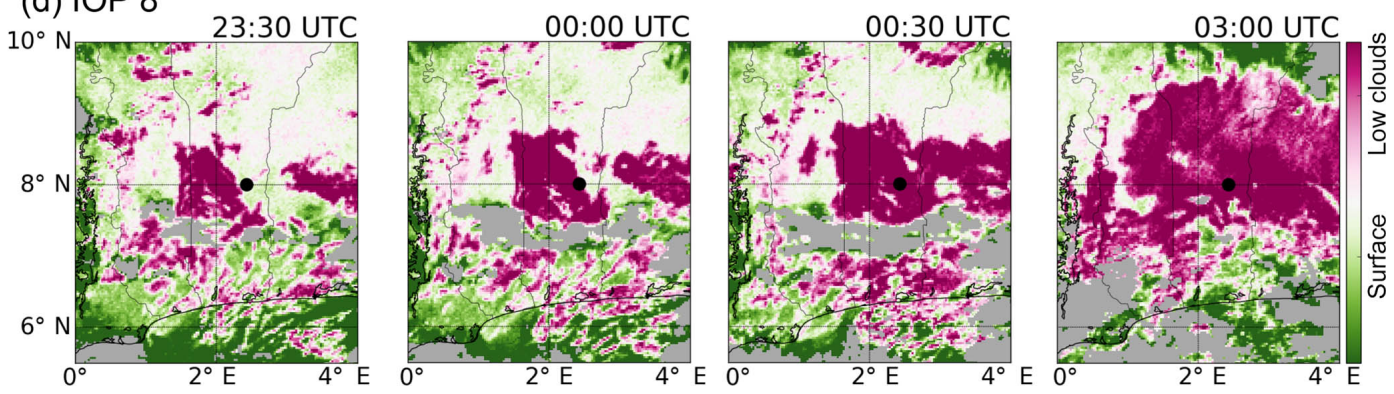

Figure 6. Brightness temperature difference of the thermal-infrared channel at 10.8 and $3.9 \mu \mathrm{m}$ for IOP 3 (a), 4 (b), 7 (c) and 8 (d). Purple color indicates LLCs. The gray shading marks areas where the brightness temperature of the $10.8 \mu \mathrm{m}$ channel exceeds $283 \mathrm{~K}$, as an indicator for higher-level clouds. The maximum and minimum values of the color scale are 3.5 and -1.0 , respectively. The location of Savè is indicated by the black marker.

$z / \mathrm{CBH}=2$. Specific humidity changes little during the stable phase and jet phase, while it is about $1 \mathrm{~g} \mathrm{~kg}^{-1}$ lower during the stratus phase (Fig. 7c). The stable phase is characterized by a shallow surface inversion and a weakly stably stratified residual layer above (Fig. 7b and d). During the jet phase the surface inversion is eroded and static stability becomes more constant with height but has quite a large standard deviation. During the stratus phase, static stability below and also above the $\mathrm{CBH}$ decreases compared to the jet phase. This is likely driven by longwave cooling at cloud top that leads to mixing. The top of the layer with reduced stability coincides with the LLJ axis during the stratus phase. This suggests that the 

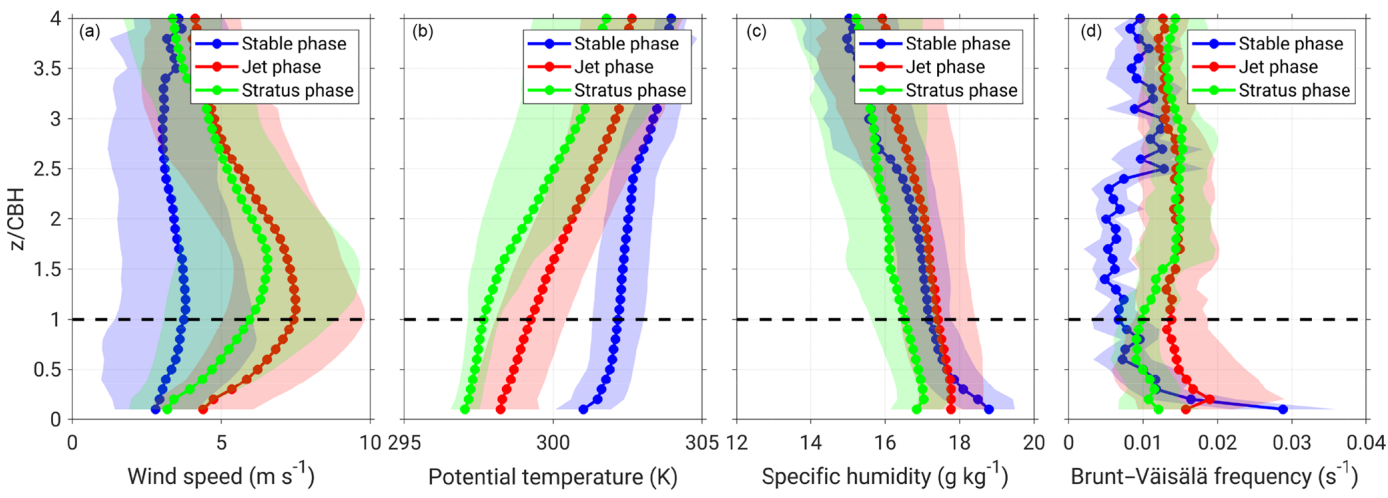

Figure 7. Mean profiles of horizontal wind speed (a), potential temperature (b), specific humidity (c) and Brunt-Väisälä frequency (d) averaged for the stable phase, jet phase and stratus phase. The shading indicates the standard deviation. The number of profiles used for the averaging are 6 for the stable phase, 37 for the jet phase and 52 for the stratus phase. Before averaging, the profiles are normalized with the median $\mathrm{CBH}$ for each IOP.
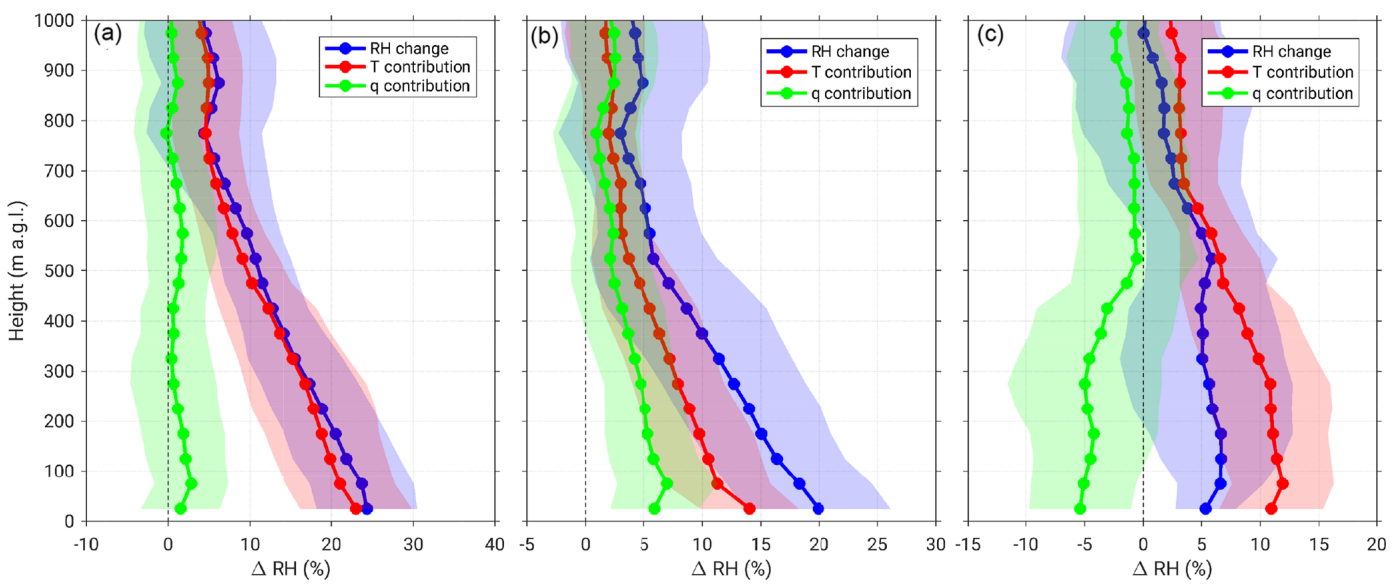

Figure 8. Mean profiles of relative humidity changes (RH change) and the contributions by temperature ( $T$ contribution) and specific humidity ( $q$ contribution) changes between 17:00 UTC and the end of the jet phase (a), between 17:00 UTC and the beginning of the jet phase $(\mathrm{P} 1, \mathrm{~b})$ and between the beginning and end of the jet phase (P2, c) averaged for all IOPs. For an overview of the considered time periods see Fig. 2. The shading indicates the standard deviation. Note that in (c), IOPs 4 and 14 are not considered because not enough soundings exist for period P2.

upward shift of the inversion due to the reduced stability in the presence of clouds causes the LLJ axis to shift upwards, which agrees with the results of Babic et al. (2018) and Dione et al. (2018).

\section{Changes in atmospheric conditions and processes leading to LLC formation}

\subsection{Relative humidity changes}

For LLCs to form, the ABL has to be saturated, i.e., relative humidity has to reach $100 \%$. In order to understand why saturation is reached, i.e., due to cooling or an increase in specific humidity, we calculate the contribution of temperature and specific humidity changes to the relative humidity changes between the late afternoon and just before the on- set of LLCs (the formula is given in Babic et al., 2018, and the time interval for which the changes are calculated is indicated in Fig. 2). For this we use the radiosonde profiles at 17:00 UTC and the last profile before the LLC onset at Savè, i.e., the elapsed time varies between $4 \mathrm{~h}$ for IOPs $4,9,11$ and 14 and $10 \mathrm{~h}$ during IOPs 1,3 and 15 . The mean profiles of relative humidity change and the individual contributions for this period are shown in Fig. 8a. On the average, relative humidity increased by about $25 \%$ near the surface, decreasing linearly with height up to around $750 \mathrm{~m}$ a.g.l. The shape of this profile is mainly due to the linear increase in relative humidity with height in the ABL in the late afternoon. Nearly $100 \%$ of the relative humidity increase is related to cooling, while specific humidity changes contribute only little $(<3 \%$, Fig. 8a). 
To investigate this further, we split the period into two parts indicated in Fig. 2: one period between the late afternoon and just after the arrival of the maritime inflow (P1) and one period after the arrival and before the LLC onset (P2). During P1, $5 \%$ of the relative humidity increase (which is about one-quarter of the total increase) in the lower layer is caused by an increase in specific humidity (Fig. 8b), while a decrease in specific humidity lowers the relative humidity increase by about $5 \%$ during P2 (Fig. 8c). This means that an increase in specific humidity contributes to the relative humidity increase before and at the arrival of the maritime inflow at Savè. Once Savè is within the maritime inflow air mass, specific humidity decreases working against the cooling with respect to the relative humidity change. Independent of the considered period, cooling is crucial to achieve saturation in the nocturnal ABL. This is in qualitative agreement with the results for IOP 8 in Babic et al. (2018). The fact that specific humidity changes play a minor role might come a little unexpected. This is likely related to the relatively low sea surface temperature of the Gulf of Guinea limiting the specific humidity in the maritime ABL and high evapotranspiration from the dense vegetation over land leading to high specific humidity in the continental ABL.

\subsection{Heat budget terms}

From the analysis of relative humidity changes in the previous section, we know that cooling is the key factor for LLC formation. Consequently, we continue with an analysis of the different terms of the heat budget at Savè (Eq. 1). We start with the estimation of TOT, RAD and HADV for the period from the late afternoon until the onset of LLCs, followed by an analysis of TURB during the jet phase (different periods are filed in Fig. 2).

\subsubsection{Heat budget estimates for the period from the late afternoon until LLC onset}

We calculate the profiles of TOT between the 17:00 UTC radiosonde profile and the last profile before the LLCs occur at Savè and average this over all IOPs (black curve in Fig. 9a). The cooling is strongest near the surface and decreases more or less linearly up to around $750 \mathrm{~m}$, which is consistent with the profiles of relative humidity changes (Fig. 8a). The variability in RAD between the individual IOPs is rather small and the mean cooling rates are on the order of $-0.15 \mathrm{Kh}^{-1}$ near the surface increasing with height to around $-0.1 \mathrm{~K} \mathrm{~h}^{-1}$ (green line in Fig. 9a). The mean profile of HADV averaged over all IOPs (red line) resembles the horizontal wind profiles used for the calculations with maximum values between 200 and $400 \mathrm{~m}$ a.g.1., i.e., around the level of the LLJ axis. Above around $400 \mathrm{~m}$ a.g.l. the sum of RAD and HADV is nearly equal to TOT leaving a small positive residual only. Below this height the residual gains high negative values with
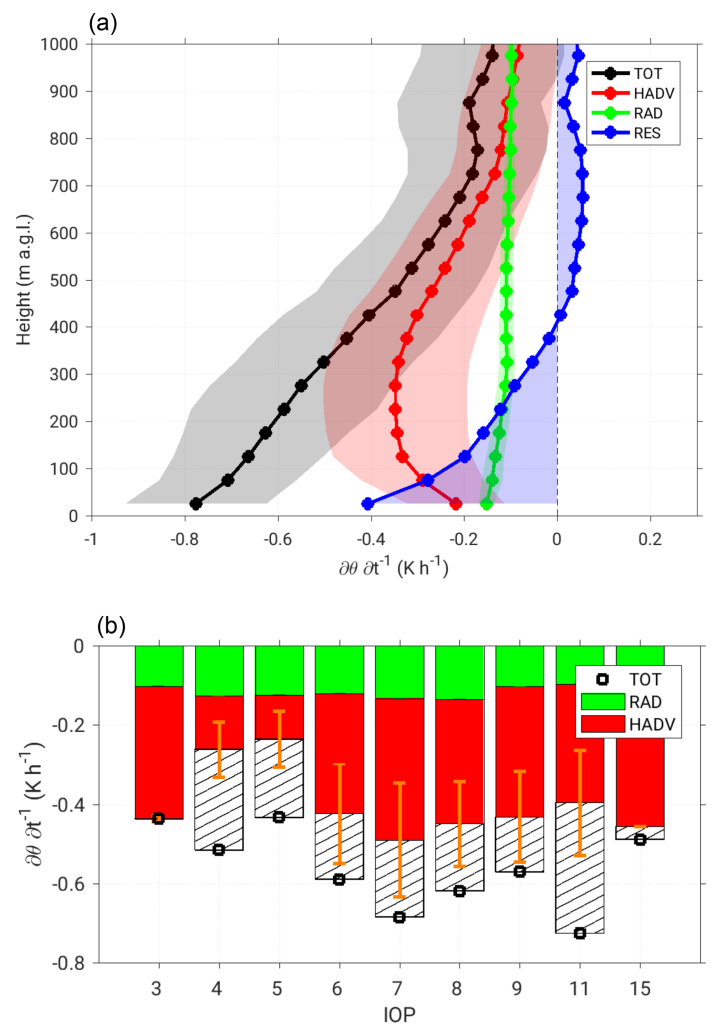

Figure 9. Mean profiles of potential temperature tendency (TOT), the contributions by horizontal advection (HADV) and radiative flux divergence (RAD) and the residual $(\mathrm{RES}=\mathrm{TOT}-\mathrm{HADV}-\mathrm{RAD})$ between 17:00 UTC and the end of the jet phase (see Fig. 2) averaged for all IOPs (a). Shading for TOT, HADV and RAD indicates the standard deviation and shading for RES marks the area between the RES and $0 \mathrm{Kh}^{-1}$. Vertically averaged TOT, RAD and HADV for individual IOPs (b). The values are averaged up to the height where TOT decreases below $1 / e$ of the maximum cooling. The hashed areas indicate the residual. The error bars for HADV result from the usage of three coastal stations and four maximum inland propagation distances of the maritime inflow to estimate HADV. Note that IOPs 1 and 14 are not considered due to missing soundings at the coast.

maximum values near the surface, i.e., the actual cooling is stronger than the contributions by HADV and RAD.

To investigate the night-to-night variability in TOT, RAD and HADV, we vertically average the different terms up to the level where TOT becomes larger than $\mathrm{TOT}_{\max } e^{-1}$ with $e$ being Euler's number and TOT $_{\max }$ the maximum cooling for each IOP (mean and median of this level are 530 and $475 \mathrm{~m}$ a.g.l., respectively). The absolute vertically averaged cooling rates are shown in Fig. 9b. TOT varies between around 0.4 and $0.8 \mathrm{~K} \mathrm{~h}^{-1}$, while the variability in RAD is small and absolute values are around $0.1 \mathrm{~K} \mathrm{~h}^{-1}$ as expected from the profiles. HADV varies considerably and reaches values from around 0.1 to $0.4 \mathrm{~K} \mathrm{~h}^{-1}$. The standard deviation of HADV (indicated by the orange error bars) that results 


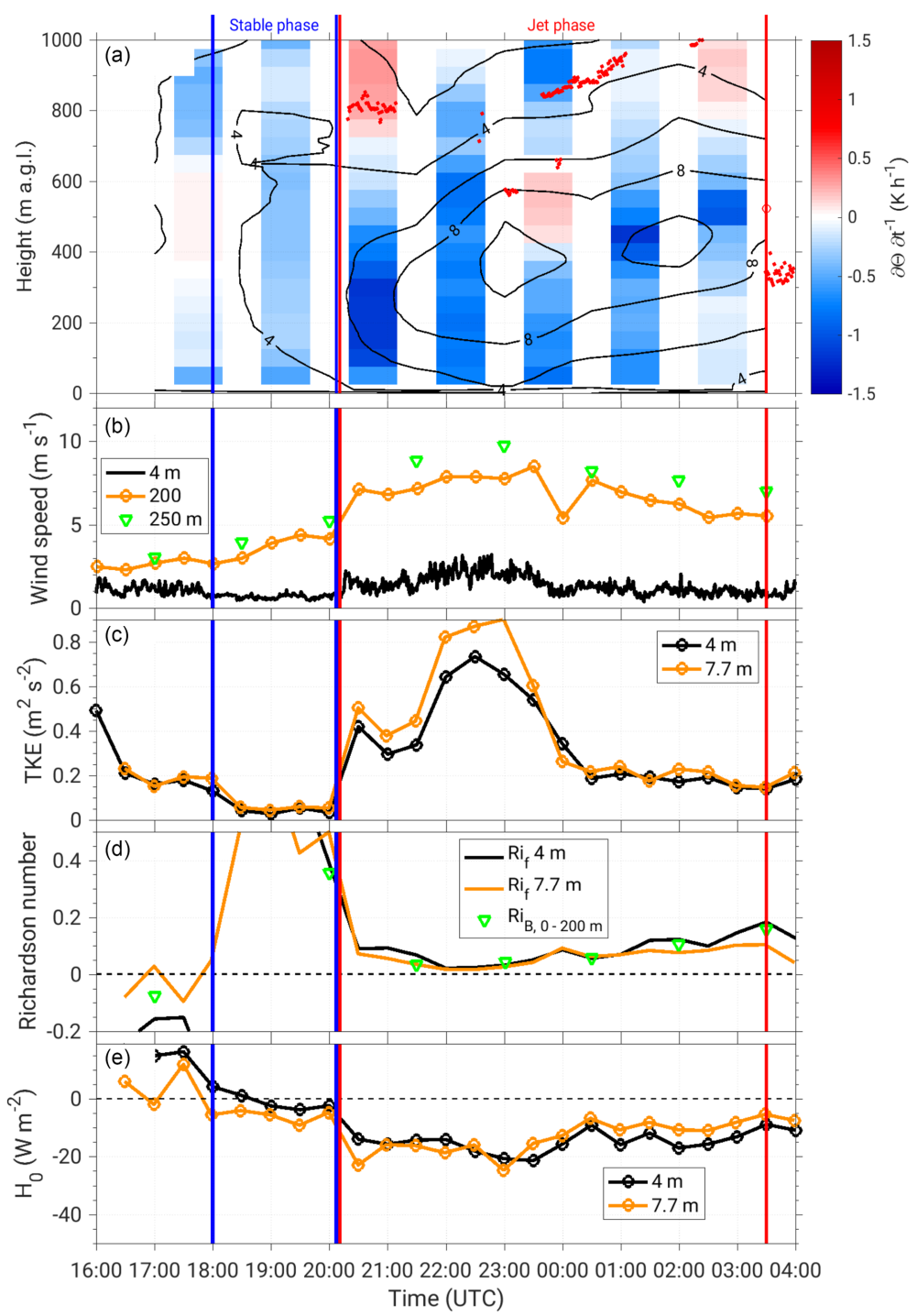

Figure 10. Time-height plot of potential temperature tendency (color coded) and horizontal wind speed (contours) from radiosondes (a); time series of horizontal wind speed from near-surface measurements at $4 \mathrm{ma.g.1.}$, Doppler lidar at $200 \mathrm{~m}$ a.g.l. and radiosondes at $250 \mathrm{~m}$ a.g.l. (b); turbulent kinetic energy, TKE (c); flux-Richardson number, $R i_{\mathrm{f}}$, and bulk-Richardson number between the surface and $200 \mathrm{~m}$ a.g.1., $R i_{\mathrm{B}, 0-200 \mathrm{~m}}(\mathbf{d})$; and surface sensible heat flux, $H_{0}$ (e) for IOP 15 . TKE, $R i_{\mathrm{f}}$ and $H_{0}$ are measured at 4 and $7.7 \mathrm{~m}$ a.g.1. Blue and red vertical lines indicate the stable phase and jet phase, respectively. In (a), each bar represents a potential temperature profile calculated and centered between consecutive soundings.

from the usage of the three coastal stations and four different maximum inland propagation distances reaches up to around $60 \%$ of the mean HADV. The relative contributions of RAD and HADV to TOT vary between $13 \%-29 \%$ and $26 \%-76 \%$ for individual IOPs. We calculate the mean and standard deviation of the relative contributions for all IOPs and find that RAD can explain about $21 \pm 4 \%$ and HADV about $50 \pm 17 \%$ of the observed cooling rates on the average. This means that about $30 \%$ of the cooling between the late afternoon and the LLC onset are caused by other processes. From the mean profiles in Fig. 9a, it is evident that most of the missing cooling occurs below around $400 \mathrm{~m}$ a.g.l. We expect that a large part of the missing cooling is related to TURB, which is further investigated in the following section.

\subsubsection{Sensible heat flux divergence during the jet phase}

The period before the LLCs form can roughly be divided into two phases, i.e., the stable phase and the jet phase (Fig. 2). These phases are illustrated using the example of IOP 15 (Fig. 10): the stable phase lasting from around sunset to 20:00 UTC is characterized by the evolution of a shallow surface inversion (Fig. 10a), relatively weak winds (Fig. 10a and b), low TKE values near the surface (Fig. 10c), strong 
stability as indicated by large flux- and bulk-Richardson numbers (Fig. 10d) and small negative sensible heat fluxes (Fig. 10e). The bulk-Richardson number is calculated for the layer between the surface and $200 \mathrm{~m}$ a.g.l. as this depicts the height of the mean wind speed maximum (not shown). With the arrival of the maritime inflow and the embedded LLJ at around 20:00 UTC, differential cooling occurs below around $500 \mathrm{~m}$ a.g.l., which is strongest between around 100 and $300 \mathrm{~m}$ a.g.l. (Fig. 10a) and reduces the static stability. At the same time wind speed in the residual layer increases sharply with a LLJ axis near $250 \mathrm{~m}$ a.g.l., which increases the dynamically induced turbulence. Both processes lead to an abrupt decrease in Richardson number to values close to zero (Fig. 10d). Simultaneously, near-surface TKE increases rapidly (Fig. 10c) and surface sensible heat flux decreases to values of around $-20 \mathrm{~W} \mathrm{~m}^{-2}$ (Fig. 10e). This marks the onset of the jet phase. The concurrent LLJ and high near-surface TKE values agrees with observations at Nangatchori in central Benin (Lothon et al., 2008). The jet phase lasts until LLCs form at around 03:30 UTC (Fig. 10a). After around midnight, TKE decreases (Fig. 10c) and stability slightly increases (Fig. 10d), which is likely related to an upward shift of the LLJ axis to around 400 ma.g.l. (Fig. 10a), which reduces the vertical wind shear below the LLJ axis. The measurements during IOP 15 show a relationship between the Richardson number and near-surface TKE. This is also the case for the other IOPs: near-surface TKE is clearly related to the flux-Richardson number and the bulkRichardson number (Fig. 11). High TKE values (larger than $0.3 \mathrm{~m}^{2} \mathrm{~s}^{-2}$ ) only occur when the Richardson numbers are below 0.1 indicating a regime where turbulence is dynamically generated. The correlation between low bulk-Richardson numbers and high TKE values indicates that turbulence is generated up to at least $200 \mathrm{~m}$ a.g.l.

The comparison of the temporal evolution of the potential temperature tendency profiles for IOP 15 (Fig. 10a) with the mean temperature tendency between late afternoon and LLC onset (Fig. 9a) suggests that a large part of the cooling below the LLJ axis happens during the jet phase (except for the shallow surface inversion that forms during the stable phase). To estimate the heat budget terms, we use a time period within the jet phase confined by the first and last radiosoundings. This requires at least two radiosoundings within the jet phase, which is not the case for IOP 4 and 14, excluding these IOPs from this analysis. As the cooling due to HADV with the maritime inflow already starts before the considered time period (Fig. 2), we cannot apply the assumption for HADV from Sect. 2.3.1 to estimate HADV for this period and only calculate TOT, RAD and TURB. As described in Sect. 2.3.3, we estimate TURB for the layer below the LLJ axis using surface sensible heat flux values from both energy balance stations. TOT and RAD are vertically averaged up to the height of the LLJ axis. When calculating the mean and standard deviation of the relative contribution of RAD and TURB to TOT for all IOPs - like we did

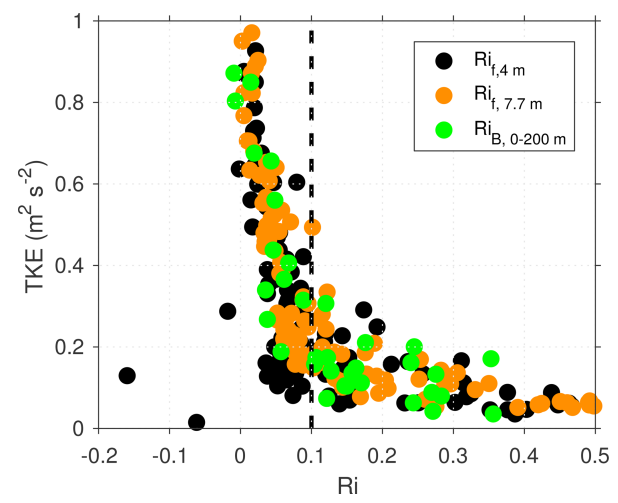

Figure 11. Relationship between turbulent kinetic energy, TKE, and Richardson number, $R i$, for the cloud-free time periods between 18:30 and 06:00 UTC during all IOPs. TKE is always measured at $4 \mathrm{~m}$ a.g.l., while flux-Richardson numbers are measured at $4 \mathrm{~m}$ a.g.l., $R i_{\mathrm{f}, 4 \mathrm{~m}}$, and $7.7 \mathrm{~m}$ a.g.1., $R i_{\mathrm{f}, 7.7 \mathrm{~m}}$, and bulk-Richardson numbers are calculated between the surface and $200 \mathrm{~m}$ a.g.l. using radiosonde data, $R i_{\mathrm{B}, 0-200 \mathrm{~m}}$.

in Sect. 5.2.1 - we find that each RAD and TURB explain about $22 \pm 10 \%$ of TOT (Fig. 12). We speculate that a large part of the residual during this period is related to horizontal advection with the maritime inflow. Furthermore, we expect vertical advection (which we cannot estimate) and horizontal advection related to temperature difference on a regional scale (which we also cannot estimate from the existing measurements) to contribute to TOT as well.

\subsection{Trigger mechanisms of LLCs}

While horizontal cold air advection contributes significantly to the cooling of the ABL and is thus a necessary precondition for LLCs (Sect. 5.1 and 5.2), the LLCs themselves are not necessarily advected as seen in the satellite images (Sect. 3), but also form locally. We assess the possibility of three mechanisms triggering the LLCs. First, during some nights, LLCs form over higher terrain, suggesting that orographic lifting constitutes the final trigger mechanism, which confirms the results of numerical simulations by Schuster et al. (2013) and Adler et al. (2017).

The second possible mechanism is related to shear in the nocturnal ABL. Zhu et al. (2001) study how the formation of shear-driven idealized clouds in the nocturnal ABL is related to land-surface and $\mathrm{ABL}$ processes using a simple well-mixed boundary layer theory. In the presence of vertical wind shear, these authors divide the nocturnal ABL into three parts: a surface layer, a mixed layer and a transition zone at the top of the nocturnal ABL. As long as the well-mixed conditions are met, a relationship between the nocturnal clouds and the lifting condensation level (LCL) calculated from surface data exists, i.e., the cloud base is around the LCL. Zhu et al. (2001) assume that the nocturnal clouds form due to processes related to the land surface and the $\mathrm{ABL}$ when the 


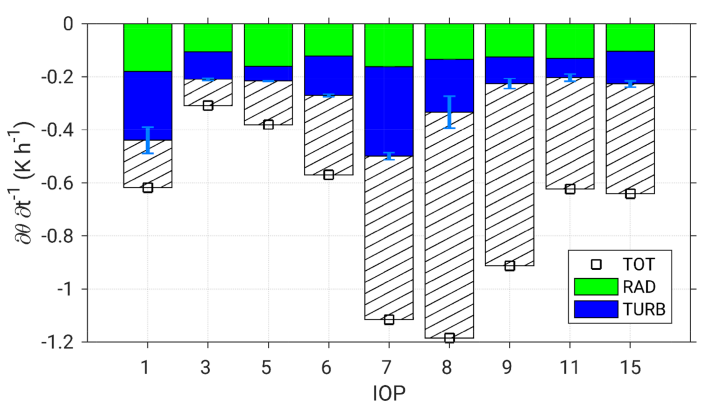

Figure 12. Vertically averaged temperature tendency (TOT), radiative flux divergence (RAD) and sensible heat flux divergence (TURB) for individual IOPs. The values are averaged up to the height of the LLJ axis and calculated for a period within the jet phase (Fig. 2). The hashed area indicates the amount of cooling that cannot be explained by neither RAD nor TURB. The error bar for TURB results from the usage of the surface sensible heat fluxes from two energy balance stations.

LCL is lower than the nocturnal ABL height, i.e., when the LCL is within the mixed layer. We calculate the LCL from air temperature, $T$, and dew point temperature, $T_{\mathrm{d}}$, measurements at $2 \mathrm{~m}$ a.g.l. with the equation $\mathrm{LCL}=125\left(T-T_{\mathrm{d}}\right)$ (e.g., Romps, 2017), and compare it to the observed CBH. We find two distinct types: during IOPs 1, 5, 6 and 8 the $\mathrm{CBH}$ agrees pretty well with the LCL, while during the other IOPs the CBH is up to several $100 \mathrm{~m}$ higher than the LCL (examples for both types are shown in Fig. 13a and b). From radiosoundings performed during the stratus phase we calculate the bulk-Richardson number for the subcloud layer as an indicator for turbulent mixing and find a relationship between the stability in the subcloud layer and the difference between $\mathrm{CBH}$ and LCL (Fig. 13c). When the CBH coincides with the LCL, bulk-Richardson numbers are very small or even negative. This indicates that during nights when the $\mathrm{CBH}$ equals the LCL the subcloud layer is near-neutrally stratified and the subcloud layer is coupled to the surface, i.e., according to Zhu et al. (2001) the LLCs are triggered by shear-related ABL processes for these cases. Interestingly, all IOP nights with low CBHs, i.e., below 130 m a.g.l. (Sect. 3), are also nights when the subcloud layer is coupled to the surface. On the other hand, when the CBH is larger than the LCL, there is no coupling and other processes must be responsible for the triggering of LLCs.

The third mechanism relates to the expansion of LLCs to the upstream side, i.e., when new LLCs are triggered upstream of existing LLCs (Sect. 3). This upstream expansion of LLCs also occurs in the numerical simulations by Adler et al. (2017). These authors identify a growth mechanism related to a modification in the stratification and LLJ profile in the model: in areas covered with LLCs, maximum static stability and the LLJ axis occur in the upper part of the LLC layer and are thus shifted upwards compared to cloud-free areas (where the LLJ axis is near CBH). This results in horizon-
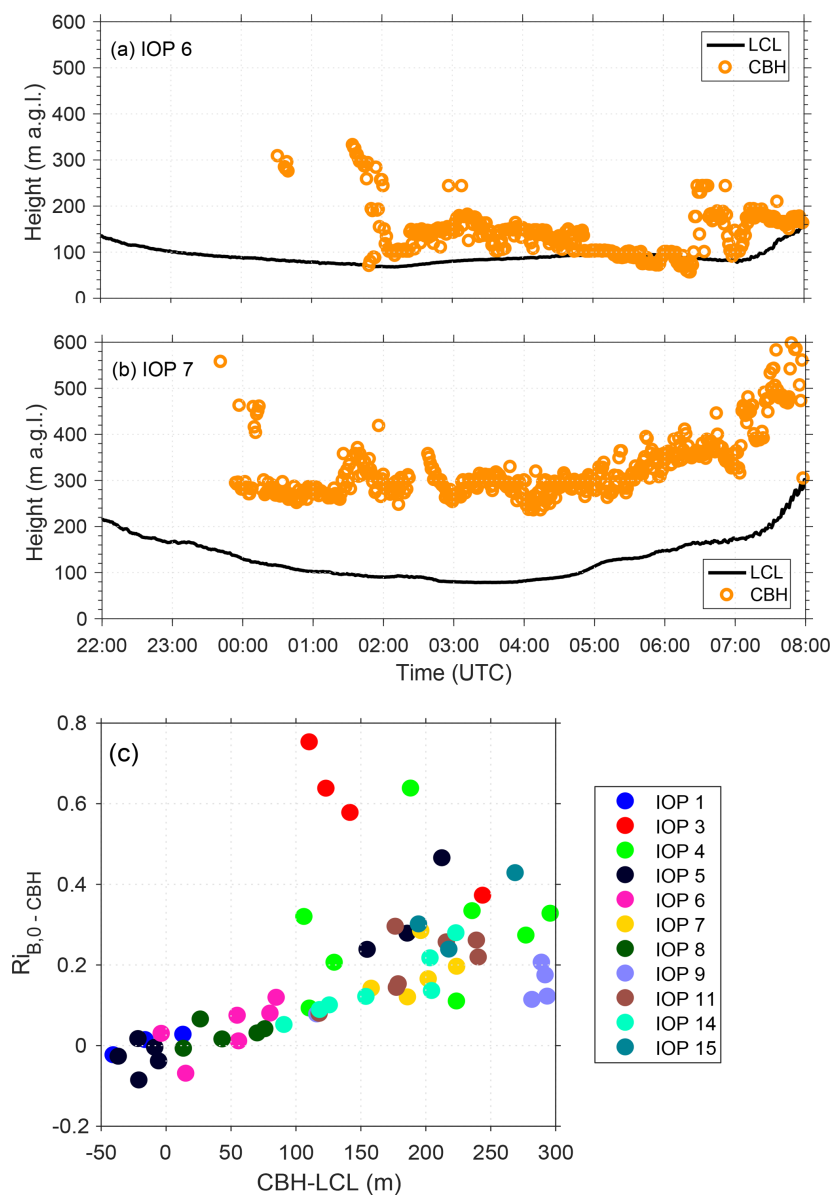

Figure 13. Cloud-base height $(\mathrm{CBH})$ measured by ceilometer and lifting condensation level (LCL) calculated from surface measurements at 2 ma.g.l. for IOPs 6 (a) and 7 (b). Relationship between the bulk-Richardson number calculated from radiosoundings for the subcloud layer $\left(R i_{\mathrm{B}, 0-\mathrm{CBH}}\right)$ and the difference between $\mathrm{CBH}$ and LCL (c).

tal convergence upstream of existing clouds and enhanced upward motion that causes additional cooling and triggers new clouds. We find observational evidence for this mechanism in the temperature and wind profiles from radiosoundings: the mean profiles reveal that static stability below and in the LLCs decreases during the stratus phase compared to the jet phase (Fig. 7b and d), which we assume to represent the conditions in the cloud-free areas. When looking at individual nights it is also evident that static stability increases around CTH (this feature is obscured in the mean profiles). The mean LLJ axis shifts upwards towards the top of the layer with lower stability during the stratus phase (Fig. 7a and d). The upward shift (often associated with a weakening) of the LLJ in the presence of LLCs is nicely visible during IOPs 3, 4, 8 and 15 in Fig. 3b, c, g and k. Even so we cannot directly measure the horizontal convergence upstream of LLCs triggering new clouds, the observed impact of the LLCs on stability and horizontal wind profiles 
strongly suggests that the mechanisms proposed by Adler et al. (2017) occur in reality and may explain the upstream expansion of LLCs.

Although we find observational evidence for all three possible mechanisms, their further analysis requires spatial information on the dynamic and thermodynamic conditions, which are not available from the observations at Savè, but could be investigated by combining the observations with numerical simulations.

\section{Discussion}

We discuss and relate the observed processes relevant for LLC formation with the processes postulated in former numerical studies. From the radiosonde data we estimate different terms of the heat budget and find that HADV with the maritime inflow accounts for about $50 \%$ of the observed cooling at Savè (Sect. 5.2.1). Despite the uncertainty arising from the estimation of HADV (Sect. 2.3.1 and Figs. 4 and 9), we are confident that HADV actually depicts the largest contribution to TOT before LLCs form. This confirms the model case study of Adler et al. (2017) who estimated heat budget terms from the $15 \mathrm{~min}$ model output for an area around Savè and the model study of Schuster et al. (2013) who calculated mean heat budget terms over $12 \mathrm{~h}$ periods (18:00-06:00 UTC) for cloudy and clear nights and averaged along a southwest-to-northeast cross section. Schuster et al. (2013) found a cooling of around $5 \mathrm{~K}$ per 12 hours with advection being the largest contribution at some distance from the coast. This value is similar to the overall potential temperature change between the stable phase and stratus phase (Fig. 7b). The absolute values of RAD derived with the radiative transfer model are on the same order of magnitude as the modeled contribution by Schuster et al. (2013). We estimate TURB to cause about $22 \%$ of TOT during the jet phase. The relevance of turbulent mixing below the LLJ axis is supported by profiles of radial velocity variance estimated from azimuthal Doppler lidar scans at $15^{\circ}$ elevation angle, which show higher values in the shear layers above and below the LLJ axis (Babić et al., 2018). This confirms findings by Schrage and Fink (2012), Schuster et al. (2013) and Adler et al. (2017). Unfortunately, no general quantification of the turbulence is possible from the observations, although two Doppler lidars were deployed at Savè. It turned out to be difficult to obtain reliable measurements of vertical velocity fluctuations from the lidars during the night as absolute values were very small. In the nocturnal ABL over the southern Great Plains in the United states, where a strong LLJ develops during the night, Bonin et al. (2015) successfully used Doppler lidar measurements to relate the vertical velocity variance to the bulk wind shear caused by the LLJ. When wind speed exceeds a certain height-dependent threshold, strong bulk shear-generated turbulence develops. With wind speed values below this threshold, no significant tur- bulence is detected by the Doppler lidars. At $200 \mathrm{~m}$ a.g.l., i.e., around the mean LLJ height at Savè, their threshold is around $15 \mathrm{~m} \mathrm{~s}^{-1}$. As the LLJ at Savè hardly ever exceeds this value, this might explain why the Doppler lidars at Savè did not detect turbulence below the LLJ, although the weak stable stratification indicates that vertical mixing is present. We assume that the problem of the Doppler lidars to detect velocity fluctuations below a certain strength are related to the size of the volume, which depends on range gate length and beam width, for which the velocities are calculated. Velocity fluctuations within the volume cannot be resolved and the estimated radial velocity is an average over the whole volume. Thus, small-scale vertical velocity fluctuations may exist but were not detected by the lidars.

Adler et al. (2017) hypothesize that gravity waves that form in the stably stratified layer around the LLJ axis contribute to a cooling due to vertical cold air advection and lead to cloud formation in the wave crests. The existence of gravity waves could neither be verified nor disproved by the observations. On the one hand, vertical velocity measurements with the Doppler lidars during the night were not reliable as described above and, on the other hand, no in situ aircraft measurements were conducted during the night.

From the radiosonde observations at Savè during IOP nights, we find a strong relationship between a decrease in temperature and a very sudden increase in horizontal wind speed with an LLJ-shaped profile, which is why we attribute both these changes to the arrival of the maritime inflow. Note that this relationship is less clear when using continuous remote sensing instruments and different objective criteria to detect the onset times (Dione et al., 2018). We assume that the relaxation of friction force leads to the formation of the LLJ-shaped profile within the maritime inflow. As the maritime inflow generally dominates the ABL conditions a few hours after sunset, there is not enough time for a pronounced LLJ to form locally without the influence of the maritime inflow. Based on the observational evidence, we therefore propose that the LLJ we observe at Savè is mainly linked to the maritime inflow and does not form locally. That means that the circumstances leading to LLJ formation differ from those relevant for regions further in the north of southern West Africa, i.e., for the Sahel or Sahara (e.g., Lothon et al., 2008). These authors attribute the formation of the LLJ to the relaxation of the friction force after sunset and to the temperature and pressure gradients related to the Saharan heat low. As the regions further north are affected much later if at all by the maritime inflow, the LLJ forms locally and is not linked to the maritime inflow.

\section{$7 \quad$ Summary and conclusions}

Eleven IOP nights from the DACCIWA ground-based field campaign conducted in southern West Africa during the summer monsoon season in 2016 are analyzed in order to char- 
acterize the spatial distribution and temporal evolution of LLCs, to investigate the intranight variability of ABL conditions and to assess the relevance of processes related to LLC formation. We used comprehensive observational data obtained at a supersite near Savè (Benin) from a ceilometer and cloud radar for the vertical extent of the LLCs, a UHF wind profiler and a Doppler lidar for wind information, and energy balance stations for the near-surface energy exchange. A large part of the analysis is based on radiosoundings performed in 1 to $1.5 \mathrm{~h}$ intervals providing temperature, humidity and wind profiles in the ABL.

Based on the dynamic and thermodynamic conditions in the ABL, different nocturnal phases are distinguished (Fig. 2): a surface inversion forms after sunset when the horizontal wind speed in the monsoon layer is weak (stable phase). The jet phase starts with the arrival of the Gulf of Guinea maritime inflow, which propagates northwards during the evening. During this phase, a LLJ wind profile and differential horizontal cold air advection are prominent. Once saturation is reached, LLCs form either as stratus or stratus fractus at first. The key findings of this study are the following:

1. The vertical extent, coverage, onset time, duration, and horizontal distribution and evolution of LLCs vary considerably for individual nights. The upper boundary of LLCs ranges from 370 to $870 \mathrm{~m}$ a.g.l. and the lower boundary varies between 70 and $450 \mathrm{~m}$ a.g.l. During some nights, stratus forms very rapidly, while during other nights, stratus fractus precede stratus for several hours. LLC onset times are detected between 22:00 and 04:45 UTC. The location of the first formation of LLCs and the following horizontal expansion differs: during some nights, LLCs first occur over higher terrain, while during other nights, the location of the first formation seems to be independent of terrain features. LLCs expand to the upstream as well as to the downstream side with respect to the mean southwesterly flow.

2. The mean profiles for each of the nocturnal phases reveal some characteristic features: the surface inversion, which is present during the stable phase, gets eroded during the jet phase by differential cold air advection and shear-generated turbulence. During the stratus phase, static stability below and within the LLC layer decreases compared to the jet phase. A distinct LLJ profile is visible during the jet and stratus phases, with the LLJ axis being near CBH during the jet phase and shifting upwards during the stratus phase.

3. We calculate the contributions of temperature and specific humidity changes to the relative humidity changes between the late afternoon and the LLC onset. The relative humidity increases by about $25 \%$ near the surface and decreases linearly with height up to around $750 \mathrm{~m}$ a.g.l. This increase is for the most part caused by cooling. Specific humidity contributes to the relative humidity increase before and during the arrival of the maritime inflow at the site, but specific humidity decreases once Savè is within the maritime inflow. In total, the contribution of specific humidity increase to reach saturation in the $\mathrm{ABL}$ is very small.

4. We estimate different terms of the heat budget for the time period before the LLC onset from the observations to assess which processes contribute to cooling: the temperature tendency at Savè is quantified from radiosonde measurements; the contribution by radiative flux divergence is derived from a radiative transfer model; the contribution by horizontal advection with the maritime inflow is estimated from radiosonde measurements at the coast and at Savè; and the bulk contribution by sensible heat flux divergence below the LLJ axis is assessed based on the surface sensible heat flux measurements. Strong cooling occurs at Savè up to around $750 \mathrm{~m}$ a.g.l. with a large part being caused by horizontal advection. We vertically average the different contributions and find that around $50 \%$ of the cooling before LLC formation is caused by horizontal cold air advection, while sensible heat flux divergence contributes about $22 \%$ during the jet phase. Radiative flux divergence contributes roughly $20 \%$ in the cloud-free nocturnal ABL, independent of the phase.

5. While horizontal advection of cool air with the maritime inflow is a necessary precondition for LLC formation, the LLCs are not necessarily advected, but rather triggered by other mechanisms. Besides orographic lifting, we find evidence for two more possible mechanisms leading to LLC formation: during some nights, the subcloud layer is characterized by small bulk-Richardson numbers and low static stability, which indicates that the LLCs are triggered by shear-related ABL processes. On the other hand, we find that the LLCs impact the wind profile by shifting the LLJ axis upwards towards the cloud top, compared to cloud-free conditions. This supports the hypothesis of the modeling study by Adler et al. (2017) that horizontal convergence upstream of existing LLCs due to the upward shift of the LLJ axis triggers new LLCs

By using observational data of 11 nights we are thus able to identify relevant processes for LLC formation, to quantify different terms of the heat budget, to identify typical dynamic and thermodynamic profiles for the different nocturnal phases, and to confirm hypotheses based on numerical simulations. The results can, on the one hand, serve for the validation of high-resolution or large-eddy simulations and, on the other hand, be used to identify flaws in global and climate models, which might add to the problems of these models to correctly simulate the LLCs and the West African monsoon system. Furthermore, this study adds to the development of a 
conceptual model explaining the evolution, maintenance and dissolution of the LLCs, which will be based on the observational and numerical analysis within the DACCIWA project.

Data availability. After the DACCIWA embargo period, the data used in this study will be available on the SErvice de DOnnées de l'OMP (SEDOO) database (Derrien et al., 2016; Handwerker et al., 2016; Kohler et al., 2016; Wieser et al., 2016).

Author contributions. BA wrote the paper with contributions from all co-authors. BA carried out the data analysis and prepared most of the figures. HA provided the satellite images. KB, NK, FL, ML, $\mathrm{CD}$ and XPD contributed to the data analysis and interpretation of results and BA, NK, FL, ML, CD and XPD conducted the groundbased measurements.

Competing interests. The authors declare that they have no conflict of interest.

Special issue statement. This article is part of the special issue "Results of the project "Dynamics-aerosol-chemistry-cloud interactions in West Africa" (DACCIWA) (ACP/AMT inter-journal SI)". It is not associated with a conference.

Acknowledgements. The DACCIWA project has received funding from the European Union Seventh Framework Programme (FP7/2007-2013) under grant agreement no. 603502. We also want to thank the staff of KIT (Karlsruhe Institute of Technology) and UPS (Université Toulouse) for helping to install and run the equipment as well as those from Institute of Agricultural Research of Benin, Cotonou, (INRAB) in Savè for allowing the equipment to be used on their grounds. Further, we are grateful to Andreas Fink of KIT and his group for performing the radiosoundings at Accra and Christine Chiu for providing the SBDART code.

The article processing charges for this open-access publication were covered by a Research

Centre of the Helmholtz Association.

Edited by: Susan van den Heever

Reviewed by: three anonymous referees

\section{References}

Adler, B., Kalthoff, N., and Gantner, L.: Nocturnal low-level clouds over southern West Africa analysed using highresolution simulations, Atmos. Chem. Phys., 17, 899-910, https://doi.org/10.5194/acp-17-899-2017, 2017.

Babić, K., Adler, B., Kalthoff, N., Andersen, H., Dione, C., Lohou, F., Lothon, M., and Pedruzo-Bagazgoitia, X.: The observed diurnal cycle of nocturnal low-level stratus clouds over southern West Africa: a case study, Atmos. Chem. Phys. Discuss., https://doi.org/10.5194/acp-2018-776, in review, 2018.

Bajamgnigni Gbambie, A. and Steyn, D.: Sea breezes at Cotonou and their interaction with the West African monsoon, Int. J. Climatol., 33, 2889-2899, 2013.

Bauer-Pfundstein, M. R. and Görsdorf, U.: Target separation and classification using cloud radar Doppler-spectra, in: Proceedings 33rd Intern. Conf. on Radar Meteorology, Cairns, Australia, 2007.

Bessardon, G., Brooks, B., Abiye, O., Adler, B., Ajao, A., Ajileye, O., Altstädter, B., Amekudzi, L. K., Aryee, J. N. A., Atiah, W. A., Ayoola, M., Babić K., Bärfuss, K., Bezombes, Y., Bret, G., Brilouet, P.-E., Cayle-Aethelhard, F., Danuor, S., Delon, C., Derrien, S., Dione, C., Durand, P., Fosu-Amankwah, K., Gabella, O., Groves, J., Handwerker, J., Kalthoff, N., Kohler, M., Kunka, N., Jambert, C., Jegede, G., Lampert, A., Leclercq, J., Lohou, F., Lothon, M., Medina, P., Pätzold, F., Pedruzo Bagazgoitia, X., Reinares, I., Sharpe, S., Smith, V., Sunmonu, L. A., Tan, N., and Wieser, A.: A dataset of the 2016 monsoon season meteorology in southern West Africa - an overview from the DACCIWA campaign, Sci. Data, in review, 2018.

Bonin, T. A., Blumberg, W. G., Klein, P. M., and Chilson, P. B.: Thermodynamic and turbulence characteristics of the southern great plains nocturnal boundary layer under differing turbulent regimes, Bound.-Lay. Meteorol., 157, 401-420, 2015.

Deetz, K., Vogel, H., Knippertz, P., Adler, B., Taylor, J., Coe, H., Bower, K., Haslett, S., Flynn, M., Dorsey, J., Crawford, I., Kottmeier, C., and Vogel, B.: Numerical simulations of aerosol radiative effects and their impact on clouds and atmospheric dynamics over southern West Africa, Atmos. Chem. Phys., 18, 9767-9788, https://doi.org/10.5194/acp-18-9767-2018, 2018.

Derrien, S., Bezombes, Y., Bret, G., Gabella, O., Jarnot, C., Medina, P., Piques, E., Delon, C., Dione, C., Campistron, B., Durand, P., Jambert, C., Lohou, F., Lothon, M., Pacifico, F., and Meyerfeld, Y.: DACCIWA field campaign, Savè super-site, UPS instrumentation, SEDOO OMP, https://doi.org/10.6096/dacciwa.1618, 2016.

Dione, C., Lohou, F., Lothon, M., Adler, B., Babić, K., Kalthoff, N., Pedruzo-Bagazgoitia, X., Bezombes, Y., and Gabella, O.: Low Level Cloud and Dynamical Features within the Southern West African Monsoon, Atmos. Chem. Phys. Discuss., https://doi.org/10.5194/acp-2018-1149, in review, 2018.

Flamant, C., Knippertz, P., Fink, A. H., Akpo, A., Brooks, B., Chiu, C. J., Coe, H., Danuor, S., Evans, M., Jegede, O., Kalthoff, N., Konaré, A., Liousse, C., Lohou, F., Mari, C., Schlager, H., Schwarzenboeck, A., Adler, B., Amekudzi, L., Aryee, J., Ayoola, M., Batenburg, A. M., Bessardon, G., Borrmann, S., Brito, J., Bower, K., Burnet, F., Catoire, V., Colomb, A., Denjean, C., Fosu-Amankwah, K., Hill, P. G., Lee, J., Lothon, M., Maranan, M., Marsham, J., Meynadier, R., Ngamini, J.-B., Rosenberg, P., Sauer, D., Smith, V., Stratmann, G., Taylor, J. W., Voigt, C., and 
Yoboué, V.: The Dynamics-Aerosol-Chemistry-Cloud Interactions in West Africa Field Campaign: Overview and Research Highlights, B. Am. Meteorol. Soc., 99, 83-104, 2018.

Grams, C., Jones, S., Marsham, J., Parker, D., Haywood, J., and Heuveline, V.: The Atlantic inflow to the Saharan heat low: observations and modelling, Q. J. Roy. Meteorol. Soc., 136, 125$140,2010$.

Handwerker, J., Scheer, S., and Gamer, T.: DACCIWA field campaign, Savè super-site, Cloud and precipitation, SEDOO OMP, https://doi.org/10.6096/dacciwa.1686, 2016.

Hannak, L., Knippertz, P., Fink, A. H., Kniffka, A., and Pante, G.: Why do global climate models struggle to represent low-level clouds in the West African summer Monsoon?, J. Climate, 30, 1665-1687, 2017.

Kalthoff, N., Adler, B., Wieser, A., Kohler, M., Träumner, K., Handwerker, J., Corsmeier, U., Khodayar, S., Lambert, D., Kopmann, A., Kunka, N., Dick, G., Ramatschi, M., Wickert, J., and Kottmeier, C.: KITcube - a mobile observation platform for convection studies deployed during HyMeX, Meteorol. Z., 22, 633 647, 2013

Kalthoff, N., Lohou, F., Brooks, B., Jegede, G., Adler, B., Babić, K., Dione, C., Ajao, A., Amekudzi, L. K., Aryee, J. N. A., Ayoola, M., Bessardon, G., Danuor, S. K., Handwerker, J., Kohler, M., Lothon, M., Pedruzo-Bagazgoitia, X., Smith, V., Sunmonu, L., Wieser, A., Fink, A. H., and Knippertz, P.: An overview of the diurnal cycle of the atmospheric boundary layer during the West African monsoon season: results from the 2016 observational campaign, Atmos. Chem. Phys., 18, 2913-2928, https://doi.org/10.5194/acp-18-2913-2018, 2018.

Knippertz, P., Fink, A. H., Schuster, R., Trentmann, J., Schrage, J. M., and Yorke, C.: Ultra-low clouds over the southern West African monsoon region, Geophys. Res. Lett., 38, L21808, https://doi.org/10.1029/2011GL049278, 2011.

Knippertz, P., Coe, H., Chiu, J. C., Evans, M. J., Fink, A. H., Kalthoff, N., Liousse, C., Mari, C., Allan, R. P., Brooks, B., Danour, S., Flamant, C., Oluwagbemiga, O. J., Lohou, F., and Marsham, J. H.: The DACCIWA project: Dynamics-aerosolchemistry-cloud interactions in West Africa, B. Am. Meteorol. Soc., 96, 1451-1460, 2015.

Knippertz, P., Fink, A. H., Deroubaix, A., Morris, E., Tocquer, F., Evans, M. J., Flamant, C., Gaetani, M., Lavaysse, C., Mari, C., Marsham, J. H., Meynadier, R., Affo-Dogo, A., Bahaga, T., Brosse, F., Deetz, K., Guebsi, R., Latifou, I., Maranan, M., Rosenberg, P. D., and Schlueter, A.: A meteorological and chemical overview of the DACCIWA field campaign in West Africa in June-July 2016, Atmos. Chem. Phys., 17, 10893-10918, https://doi.org/10.5194/acp-17-10893-2017, 2017.

Kohler, M., Kalthoff, N., Seringer, J., and Kraut, S.: DACCIWA field campaign, Savè super-site, Surface measurements, SEDOO OMP, https://doi.org/10.6096/dacciwa.1690, 2016.
Legain, D., Bousquet, O., Douffet, T., Tzanos, D., Moulin, E., Barrie, J., and Renard, J.-B.: High-frequency boundary layer profiling with reusable radiosondes, Atmos. Meas. Tech., 6, 21952205, https://doi.org/10.5194/amt-6-2195-2013, 2013.

Lothon, M., Saïd, F., Lohou, F., and Campistron, B.: Observation of the diurnal cycle in the low troposphere of West Africa, Mon. Weather Rev., 136, 3477-3500, 2008.

Maranan, M., Fink, A., and Knippertz, P.: Rainfall types over southern West Africa: Objective identification, climatology and synoptic environment, Q. J. Roy. Meteorol. Soc., 144, 1628-1648, https://doi.org/10.1002/qj.3345, 2018.

Parker, D. J., Kassimou, A., Orji, B. N., Osika, D. P., Hamza, I., Diop-Kane, M., Fink, A., Galvin, J., Guichard, F., Lamptey, B. L., Hamidou, H., Linden, R., Redl, R., Lebel, T., and Tubbs, C.: Local Weather, in: Meteorology of Tropical West Africa: The Forecasters Handbook, edited by: Parker, D. J. and Diop-Kane, M., John Wiley \& Sons, Chichester, UK, 130-174, 2017.

Ricchiazzi, P., Yang, S., Gautier, C., and Sowle, D.: SBDART: A research and teaching software tool for plane-parallel radiative transfer in the Earth's atmosphere, B. Am. Meteorol. Soc., 79, 2101-2114, 1998

Romps, D. M.: Exact expression for the lifting condensation level, J. Atmos. Sci., 74, 3891-3900, 2017.

Schmetz, J., Pili, P., Tjemkes, S., Just, D., Kerkmann, J., Rota, S., and Ratier, A.: An introduction to Meteosat second generation (MSG), B. Am. Meteorol. Soc., 83, 977-992, 2002.

Schrage, J. M. and Fink, A. H.: Nocturnal continental low-level stratus over tropical West Africa: observations and possible mechanisms controlling its onset, Mon. Weather Rev., 140, 1794-1809, 2012.

Schuster, R., Fink, A. H., and Knippertz, P.: Formation and maintenance of nocturnal low-level stratus over the southern West African monsoon region during AMMA 2006, J. Atmos. Sci., 70, 2337-2355, 2013

Stull, R. B.: An introduction to boundary layer meteorology, Kluwer Academic Publishers, Dordrecht, the Netherlands, 666 pp., 1988.

Sun, J., Burns, S. P., Delany, A. C., Oncley, S. P., Horst, T. W., and Lenschow, D. H.: Heat balance in the nocturnal boundary layer during CASES-99, J. Appl. Meteorol., 42, 1649-1666, 2003.

van der Linden, R., Fink, A. H., and Redl, R.: Satellite-based climatology of low-level continental clouds in southern West Africa during the summer monsoon season, J. Geophys. Res., 120, 1186-1201, 2015.

Wieser, A., Adler, B., and Deny, B.: DACCIWA field campaign, Savè super-site, Thermodynamic data sets, https://doi.org/10.6096/dacciwa.1659, 2016.

Zhu, P., Albrecht, B., and Gottschalck, J.: Formation and development of nocturnal boundary layer clouds over the southern Great Plains, J. Atmos. Sci., 58, 1409-1426, 2001. 